\title{
Dietary $\alpha$-linolenic acid and health-related outcomes: a metabolic perspective
}

\author{
Graham C. Burdge and Philip C. Calder* \\ Institute of Human Nutrition, Developmental Origins of Health and Disease Division, University of Southampton, \\ Bassett Crescent East, Southampton SO16 7PX, UK
}

\begin{abstract}
$\alpha$-Linolenic acid ( $\alpha$ LNA; 18:3n-3) is essential in the human diet, probably because it is the substrate for the synthesis of longer-chain, more unsaturated $n-3$ fatty acids, principally EPA $(20: 5 n-3)$ and DHA (22:6n-3), which confer important biophysical properties on cell membranes and so are required for tissue function. The extent to which this molecular transformation occurs in man is controversial. The present paper reviews the recent literature on the metabolism of $\alpha$ LNA in man, including the use of dietary $\alpha$ LNA in $\beta$-oxidation, recycling of carbon by fatty acid synthesis de novo and conversion to longer-chain PUFA. Sex differences in $\alpha$ LNA metabolism and the possible biological consequences are discussed. Increased consumption of EPA and DHA in fish oil has a number of well-characterised beneficial effects on health. The present paper also reviews the efficacy of increased $\alpha$ LNA consumption in increasing the concentrations of EPA and DHA in blood and cell lipid pools, and the extent to which such dietary interventions might be protective against CVD and inflammation. Although the effects on CVD risk factors and inflammatory markers are variable, where beneficial effects have been reported these are weaker than have been achieved from increasing consumption of $\mathrm{EPA}+\mathrm{DHA}$ or linoleic acid. Overall, the limited capacity for conversion to longer-chain $n-3$ fatty acids, and the lack of efficacy in ameliorating CVD risk factors and inflammatory markers in man suggests that increased consumption of $\alpha$ LNA may be of little benefit in altering $\mathrm{EPA}+\mathrm{DHA}$ status or in improving health outcomes compared with other dietary interventions.
\end{abstract}

$\alpha$-Linolenic acid: Human metabolism: Cardiovascular disease: Inflammation

\section{Introduction}

$\alpha$-Linolenic acid ( $\alpha$ LNA; $18: 3 n-3)$ is an essential fatty acid in the human diet and is the most abundant $n$ - 3 PUFA in the Western diet. The present review will focus on two main areas of the biology of $\alpha$ LNA in human adults; its metabolism and its effect on CVD and inflammation.

The major dietary sources of $\alpha$ LNA are green leaves, and oils used in cooking such as rapeseed oil and soyabean oil where it accounts for up to $10 \%$ of total fatty acids. Flaxseed (also known as linseed) oil, which is commonly consumed as a dietary supplement, is particularly rich in $\alpha$ LNA ( $>50 \%$ total fatty acids). Typical consumption of $\alpha$ LNA in Europe, Australia and North America ranges from 0.6 to $1.7 \mathrm{~g} / \mathrm{d}$ in men and from 0.5 to $1.4 \mathrm{~g} / \mathrm{d}$ in women (Ministry of Agriculture, Fisheries \& Food, 1997; Hulshof et al. 1999; Ollis et al. 1999; Kris-Etherton et al. 2000; Innis \& Elias, 2003).

$\alpha$ LNA can be converted to longer-chain $n$-3 PUFA such as EPA (20:5n-5) and DHA (22:6n-3), and it is difficult to distinguish any function which is innate to $\alpha$ LNA from those of its longer-chain metabolites (Sinclair et al. 2000). The concentration of $\alpha$ LNA in phospholipids in plasma and in cell membranes is typically less than $0.5 \%$ of total fatty acids (Table 1). It thus seems unlikely that the amount of $\alpha$ LNA present in these pools would be able to exert a significant effect on the biophysical properties of the phospholipid membrane and so influence biological function. Typical consumption of $\alpha \mathrm{LNA}$ in Western countries is about 25- and 15-fold greater than of EPA and DHA (Ministry of Agriculture, Fisheries \& Food, 1997; Hulshof et al. 1999; Ollis et al. 1999; Astorg et al. 2004). Conversely, the concentrations of the longer-chain metabolites EPA, docosapentaenoic acid (DPA; 22:5n-3) and DHA exceed that of $\alpha$ LNA in most tissues (Table 1). This apparent mismatch between dietary intakes and concentrations in plasma and tissue lipids supports the view that the primary biological role of $\alpha \mathrm{LNA}$ is as a substrate for EPA and DHA synthesis.

\footnotetext{
Abbreviations: DPA, docosapentaenoic acid; LA, linoleic acid; $\alpha$ LNA, $\alpha$-linolenic acid; CRP, C-reactive protein; PC, phosphatidylcholine; SFA, saturated fatty acid; TAG, triacylglycerol.

* Corresponding author: Dr Philip C. Calder, fax +44 2380 594379, email pcc@soton.ac.uk
} 
Table 1. Examples of proportions of $\alpha$-linolenic acid ( $\alpha$ LNA), eicosapentaenoic acid and docosahexaenoic acid in blood, cell and tissue lipid fractions from adult human subjects

\begin{tabular}{|c|c|c|c|c|}
\hline \multirow[b]{2}{*}{ Lipid fraction } & \multicolumn{3}{|c|}{$\%$ Total fatty acids } & \multirow[b]{2}{*}{ Reference } \\
\hline & $\alpha$ LNA & EPA & $\mathrm{DHA}$ & \\
\hline Plasma phosphatidylcholine & 0.1 & 0.8 & 2.9 & Mantzioris et al. (1994) \\
\hline Plasma cholesteryl ester & 0.4 & 0.8 & 0.5 & Mantzioris et al. (1994) \\
\hline Plasma triacylglycerol & 0.8 & 0.8 & 0.5 & Mantzioris et al. (1994) \\
\hline Platelet phosphatidylcholine & 0.3 & 0.2 & $1 \cdot 1$ & Weaver et al. (1990) \\
\hline Platelet phosphatidylethanolamine & 0.2 & $0 . \overline{6}$ & $6 \cdot 3$ & Weaver et al. (1990) \\
\hline Mononuclear cell phospholipid & 0.1 & 0.3 & $2 \cdot 3$ & Caughey et al. (1996) \\
\hline Neutrophil phospholipid & NA & 0.6 & $1 \cdot 3$ & Healy et al. (2000) \\
\hline Erythrocyte phospholipid & NA & 0.8 & 3.5 & Burdge et al. (2005) \\
\hline Liver phosphatidylethanolamine & $0 \cdot 2$ & $1 \cdot 6$ & $7 \cdot 7$ & Crawford et al. (1976) \\
\hline Brain grey matter phosphatidylethanolamine & $0 \cdot 1$ & NA & $24 \cdot 3$ & Crawford et al. (1976) \\
\hline Brain grey matter phosphatidylserine & NA & NA & $36 \cdot 6$ & O’Brien \& Sampson (1965) \\
\hline Brain grey matter phosphatidylcholine & NA & NA & $3 \cdot 1$ & O’Brien \& Sampson (1965) \\
\hline Brain white matter phosphatidylethanolamine & NA & NA & $3 \cdot 4$ & O’Brien \& Sampson (1965) \\
\hline Retina phosphatidylcholine & NA & NA & $22 \cdot 2$ & Anderson (1970) \\
\hline Retina phosphatidylethanolamine & NA & NA & $18 \cdot 5$ & Anderson (1970) \\
\hline Retina phosphatidylserine & NA & NA & $4 \cdot 6$ & Anderson (1970) \\
\hline Testis total lipid extract & NA & NA & 8.5 & Bieri \& Prival (1965) \\
\hline Sperm phospholipid & NA & NA & $35 \cdot 2$ & Poulos et al. (1973); Tang et al. (1993) \\
\hline White adipose tissue & 0.7 & NA & 0.1 & Kaminskas et al. (1999) \\
\hline
\end{tabular}

NA, not available.

Human essential fatty acid deficiency is very rare and the evidence to support the essentiality of $\alpha$ LNA in the human diet is largely restricted to patients who received parenteral feeds. Of patients receiving long-term total parenteral nutrition lacking $\alpha$ LNA, $50 \%$ of children and $30 \%$ of adults exhibited visual dysfunction (Vinton et al. 1990). The DHA content of neural membrane phospholipids modulates the activities of several signalling pathways in the brain (Sinclair et al. 2000; Astorg et al. 2004) and is critical for optimal retinal function (Jeffrey et al. 2001; Mitchell et al. 2003). Thus these findings are consistent with the suggestion that lack of $\alpha$ LNA intake decreased availability of DHA for incorporation into neural membranes (Vinton et al. 1990). This conclusion is supported by the observation that the offspring of monkeys fed an $n$-3 PUFA-deficient diet during pregnancy show visual impairments (Neuringer $e t$ al. 1986) and that supplementation of the infant monkeys with $\alpha$ LNA resulted in an increase in the concentration of DHA in neural tissues and an improvement in visual function (Connor \& Neuringer, 1988).

\section{Patterns of $\alpha$-linolenic acid consumption in different nations}

While typical intakes of $\alpha$ LNA are generally regarded as being approximately $1.5 \mathrm{~g} / \mathrm{d}$ in Western populations, detailed comparison of the consumption of $\alpha$ LNA shows an almost 3-fold variation between individual nations (Fig. 1 (A)). For example, $\alpha$ LNA intake for French men is about one-third that of North American men (Fig. 1 (A)). Calculation of the linoleic acid (LA; $18: 2 n-6): \alpha$ LNA ratio in the diet also shows marked variation between nations. For example, in men the LA: $\alpha$ LNA ratio differs between 5.5 in Denmark and 13.8 in France (Fig. 1 (B)). For women, this ratio varies between 4.3 in Denmark and 13.6 in France. However, the LA: $\alpha$ LNA ratio for Spanish men and women together is 27.0 (Fig. 1 (B)). The importance of these variations in the LA: $\alpha$ LNA ratio in the diet is that the relative consumption of LA and $\alpha$ LNA modulates the extent to which $\alpha$ LNA is converted to long-chain metabolites. This will be discussed in more detail later. One potential implication is that recommendations for the intakes of $n-3$ and $n-6$ PUFA may need to be devised for individual nations according to their habitual LA and $\alpha$ LNA consumption.

\section{Bioavailability of $\alpha$-linolenic acid from the diet}

The bioavailability of $\alpha$ LNA from the diet is determined by the efficiency of absorption across the gastrointestinal tract. There is very little information regarding the absorption of $\alpha$ LNA by the human gut. Measurement of the concentrations of ${ }^{2} \mathrm{H}$-labelled fatty acids in the triacylglycerol (TAG) fraction of chylomicrons following ingestion in a single meal showed that the absorption and secretion of oleic acid (18: 1n-9), LA and $\alpha$ LNA were similar (Emken et al. 1994). Although this does not specifically measure absorption across the gut, it does indicate that the overall bioavailability of $\alpha$ LNA from a meal is similar to that of other unsaturated fatty acids. Direct assessment of absorption of $\alpha \mathrm{LNA}$ requires measurement of the output in stool compared with consumption of a known amount in a meal. To date there have been no published data from such an experiment. Measurement of the cumulative concentration of labelled $\alpha$ LNA in stool collected over $5 \mathrm{~d}$ following ingestion of $750 \mathrm{mg}\left[\mathrm{U}-{ }^{13} \mathrm{C}\right] \alpha \mathrm{LNA}$ by a single individual showed that greater than $96 \%$ of the administered dose was absorbed (GC Burdge, unpublished results). Similar levels of $\alpha$ LNA uptake have also been reported in patients with ileostomies who were fed $100 \mathrm{~g}$ linseed oil (Saunders \& Sillery, 1988). These findings suggest that absorption of $\alpha$ LNA across the gut and its secretion into the bloodstream is efficient in man. 
(A)

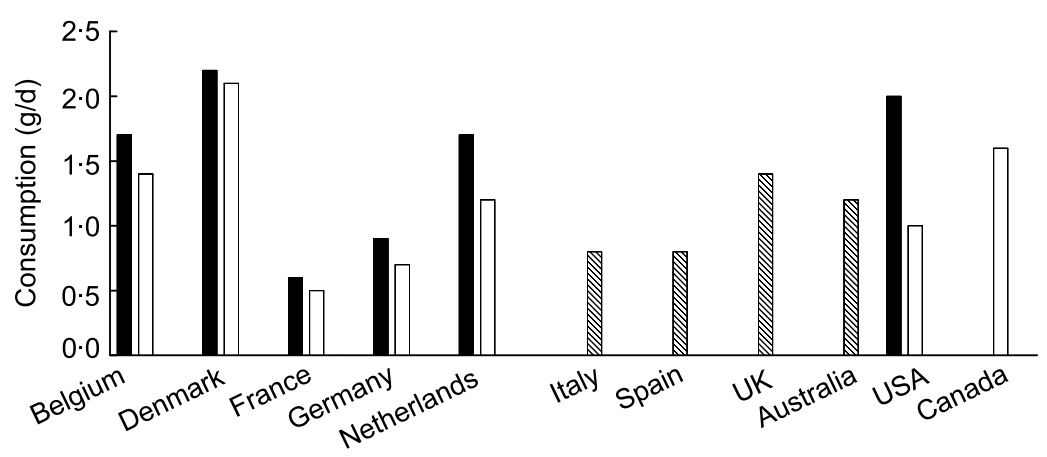

(B)

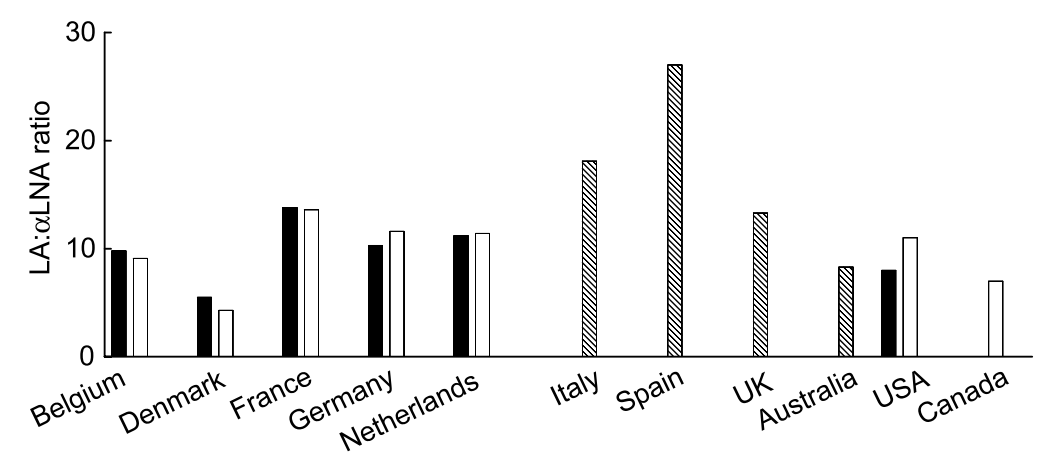

Fig. 1. Daily intakes of $\alpha$-linolenic acid ( $\alpha$ LNA) and linoleic acid (LA) in different nations for men ( $\square$ ), women ( $\square)$ and men and women ( $\mathbb{Q})$. (A) $\alpha$ LNA consumption; (B) LA: $\alpha$ LNA ratio. Values for Canada were from pregnant women. Separate data were not available for men and women from Italy, Spain, UK and Australia. (Data from Ministry of Agriculture, Fisheries \& Food, 1997; Hulshof et al. 1999; Ollis et al. 1999; Kris-Etherton et al. 2000; Innis \& Elias, 2003).

\section{$\alpha$-Linolenic acid metabolism in man}

$\alpha$ LNA which has been absorbed by the gut passes into the circulation primarily esterified to TAG carried by chylomicron particles (Burdge et al. 2002) and so is made available for uptake by tissues and incorporation into pools destined for storage, cell membranes, production of energy, mobilisation and conversion to longer-chain PUFA. The metabolic fates of $\alpha$ LNA in man are summarised in Fig. 2.

\section{Incorporation of $\alpha$-linolenic acid into adipose tissue}

Adipose tissue accounts for approximately $15 \%$ of body mass in men and $23 \%$ of body mass in women. Thus incorporation of $\alpha \mathrm{LNA}$ into this storage pool represents a potentially important route of disposal of dietary $\alpha$ LNA and a reserve pool which is available for mobilisation during periods of increased demands. $\alpha$ LNA accounts for about $0.7 \%$ of total fatty acids in neutral lipids in adipose tissue in men and women, while DHA concentration is approximately $0 \cdot 1 \%$ and EPA is practically undetectable (Tang et al. 1993; Kaminskas et al. 1999). Thus, it can be calculated that, in a $75 \mathrm{~kg}$ man with a fat mass of $15 \%$, the whole body $\alpha$ LNA reserve in adipose tissue would be approximately $79 \mathrm{~g}$ (roughly equivalent to typical intake over $53 \mathrm{~d}$ ). Likewise, in a $65 \mathrm{~kg}$ woman with a fat mass of $23 \%$, the whole body $\alpha$ LNA reserve in adipose tissue would be approximately $105 \mathrm{~g}$ (roughly equivalent to typical intake over $70 \mathrm{~d}$ ). It is conceivable that such reserves may buffer variations in dietary intake and so prevent development of deficiency of $\alpha$ LNA or of longer-chain metabolites.

During the postprandial period there is a metabolic drive to store fatty acids which is facilitated by the insulindependent increase in lipoprotein lipase activity and of fatty acid uptake in adipose tissue. In the fasting state, plasma NEFA are derived primarily from the release of adipose tissue TAG stores by the action of hormone-sensitive lipase. The exchange of $\alpha$ LNA between the blood and adipose

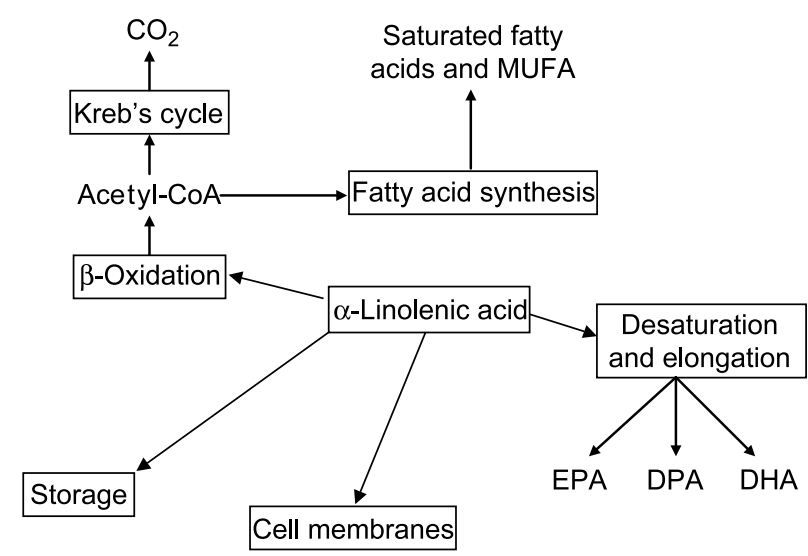

Fig. 2. Summary of the main metabolic fates of $\alpha$-linolenic acid in man. DPA, docosapentaenoic acid. 
tissue compartments has not been characterised in detail in human subjects in vivo. However, when men consumed $\left[\mathrm{U}^{13} \mathrm{C}\right] \alpha \mathrm{LNA}$, labelled $\alpha \mathrm{LNA}$ was detected in the plasma NEFA pool within $2 \mathrm{~h}$ and reached a peak at $6 \mathrm{~h}$ (Burdge et al. 2002). One interpretation is that during the early postprandial period labelled $\alpha$ LNA detected in the NEFA pool probably reflects incomplete entrapment of fatty acids released by the hydrolysis of chylomicron TAG (Evans et al. 2002). At later time points (for example, about $6 \mathrm{~h}$ ) the presence of labelled $\alpha$ LNA in plasma NEFA may reflect recently assimilated fatty acids. Overall, the rapid release of $\alpha$ LNA into the NEFA pool, together with the $\alpha$ LNA pool associated with chylomicron remnant particles, would tend to facilitate supply of $\alpha$ LNA to the liver. The concentration of $\left[{ }^{13} \mathrm{C}\right] \alpha \mathrm{LNA}$ in plasma NEFA was 2-fold greater in women than in men over $21 \mathrm{~d}$ (Burdge \& Wootton, 2002). This suggests sex differences in the metabolism of $\alpha$ LNA in storage pools and potentially greater short-term availability of $\alpha$ LNA for supply to the liver in women.

Comparison of the metabolic fates of EPA and DHA during the postprandial period showed enrichment of DHA in the plasma NEFA pool, presumably as a result of incomplete entrapment of fatty acids released by hydrolysis of chylomicron TAG, compared with EPA (Heath et al. 2003). Furthermore, there was greater incorporation of DHA than of EPA into VLDL TAG. This suggests differential uptake of PUFA released by lipoprotein lipase activity which appears to facilitate supply of DHA to the liver and remobilisation on VLDL.

\section{$\beta$-Oxidation of $\alpha$-linolenic acid}

Since $\alpha$ LNA is essential in the human diet and is consumed in relatively modest amounts, it is somewhat surprising that it is a substrate for $\beta$-oxidation and energy production. However, the appearance of ${ }^{13} \mathrm{C}$ as ${ }^{13} \mathrm{CO}_{2}$ on breath following the ingestion of ${ }^{13} \mathrm{C}$-labelled $\alpha \mathrm{LNA}$ has been clearly demonstrated in a number of studies and the area under the time $\times$ enrichment curve has been used to estimate the proportion of ingested $\alpha$ LNA used for energy production. The values produced by such calculations probably represent an approximately $30 \%$ underestimate of the actual proportion of ingested $\alpha$ LNA used in energy production due to trapping of ${ }^{13} \mathrm{CO}_{2}$ in bicarbonate pools (Irving et al. 1983). Since the period of collection of $\mathrm{CO}_{2}$ differs between reports from 9 to $48 \mathrm{~h}$, the estimates of partitioning towards $\beta$-oxidation differ from 15 to $33 \%$ (DeLany et al. 2000; Vermunt et al. 2000; Bretillon et al. 2001; Burdge et al. 2002; McCloy et al. 2004). When subjects were studied over $24 \mathrm{~h}$ under comparable conditions, the fractional $\beta$-oxidation of $\alpha \mathrm{LNA}$ in women was estimated as approximately $22 \%$ of administered dose (Burdge \& Wootton, 2002) compared with $33 \%$ in men (Burdge et al. 2002). This may reflect lower muscle mass in women, and the potential overall effect would be to increase the proportion of ingested $\alpha$ LNA available for conversion to longer-chain PUFA in women compared with men. The extent of partitioning of $\alpha$ LNA towards $\beta$-oxidation, when assessed under identical conditions, was almost twice that of palmitic, stearic and oleic acids, and greater than LA (DeLany et al. 2000) (Fig. 3 (A)). This may reflect the higher affinity of carnitine palmitoyl transferase-1 for $\alpha$ LNA (Clouet et al. 1989).

One study has reported the effect of altering the $n-3$ PUFA content of the background diet on the proportion of ingested $\left[{ }^{13} \mathrm{C}\right] \alpha \mathrm{LNA}$ recovered as ${ }^{13} \mathrm{CO}_{2}$ on breath (Burdge et al. 2003). Three groups of men matched for BMI, age and fasting plasma TAG concentrations consumed a standard meal containing $700 \mathrm{mg}\left[\mathrm{U}_{-}{ }^{13} \mathrm{C}\right] \alpha \mathrm{LNA}$ and excretion of ${ }^{13} \mathrm{CO}_{2}$ on breath was measured over $24 \mathrm{~h}$. Subjects then consumed either a control diet ( $\alpha$ LNA $1.7 \mathrm{~g} / \mathrm{d}$, EPA + DHA $0.4 \mathrm{~g} / \mathrm{d}$ ), a diet containing an increased amount of $\alpha \mathrm{LNA}$ $(\alpha$ LNA $9.6 \mathrm{~g} / \mathrm{d}$, EPA + DHA $0.4 \mathrm{~g} / \mathrm{d}$ ) or a diet containing an increased amount of EPA + DHA $(\alpha$ LNA $1.7 \mathrm{~g} / \mathrm{d}$, EPA + DHA $1.6 \mathrm{~g} / \mathrm{d}$ ) for 8 weeks. There was no difference in energy intake between the groups. The proportion of ingested labelled $\alpha$ LNA recovered as ${ }^{13} \mathrm{CO}_{2}$ on breath was then measured again. There was no significant difference between baseline and the end of the 8-week intervention period in the proportion of labelled $\alpha$ LNA partitioned towards $\beta$-oxidation in the group consuming the control, increased $\alpha$ LNA or increased EPA + DHA diets (Fig. 3 (B)). This suggests that the extent of partitioning of $\alpha$ LNA towards $\beta$-oxidation is relatively stable over short periods of time and that altering the amount of either $\alpha$ LNA or longchain $n$-3 PUFA in the diet does not significantly alter this process.

\section{Recycling of carbon from $\alpha$-linolenic acid into saturated and monounsaturated fatty acids}

In addition to conversion to $\mathrm{CO}_{2}$ by the activity of Kreb's cycle, carbon in acetyl-CoA generated by fatty acid $\beta$-oxidation may be recycled and used in fatty acid synthesis de novo. This process has been suggested to be important as a source of fatty acids in pregnant and fetal monkeys (Sheaff-Greiner et al. 1996) and rats (Cunnane et al. 1994, 2003). There is one report which describes recycling of carbon released by $\beta$-oxidation of $\alpha$ LNA in human subjects (Burdge \& Wootton, 2003). Men (35 years of age) and women (28 years of age) consumed $700 \mathrm{mg}\left[\mathrm{U}_{-}{ }^{13} \mathrm{C}\right] \alpha \mathrm{LNA}$ and the concentrations of labelled saturated fatty acids (SFA) and MUFA in plasma were measured over $21 \mathrm{~d}$. Labelled palmitic, stearic, palmitoleic and oleic acids were detected in plasma phosphatidylcholine (PC) and TAG, but not other plasma lipid pools in both men and women. The proportion of label was 6-fold greater in plasma PC compared with TAG in men and 25-fold greater in plasma PC than TAG in women. These data suggest preferential channelling of SFA and MUFA synthesised by the recycling pathway into phospholipids by the liver, which is in contrast to the molecular partitioning of the bulk of the hepatic SFA and MUFA pools towards TAG. Since typical daily consumption of $\alpha$ LNA in the UK is 25-fold and 15-fold greater than EPA and DHA, respectively (Ministry of Agriculture, Fisheries \& Food, 1997), it seems unlikely that recycling of carbon from $\alpha$ LNA simply represents a means of disposal of excess $\alpha$ LNA not required for EPA and DHA synthesis.

The total concentration of labelled SFA and MUFA in plasma lipids was $20 \%$ greater in men compared with women (Burdge \& Wootton, 2003) (Table 2). This is in agreement with greater partitioning of $\alpha \mathrm{LNA}$ towards 


\section{(A)}

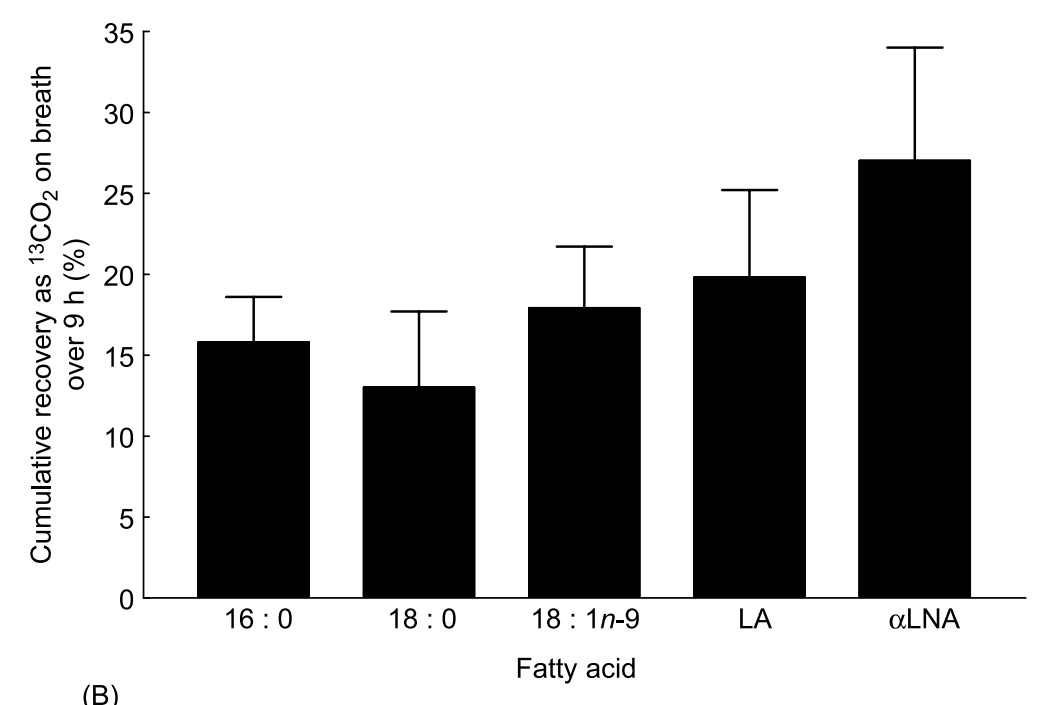

(B)

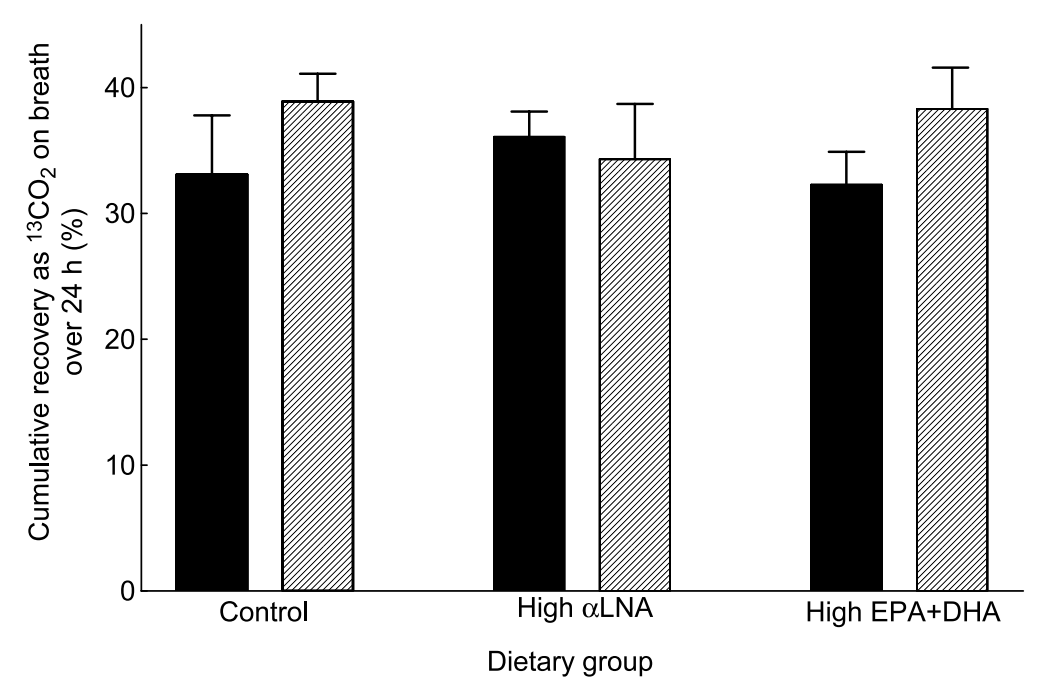

Fig. 3. Recovery of ingested $\left[{ }^{13} \mathrm{C}\right]$ fatty acids as ${ }^{13} \mathrm{CO}_{2}$ on breath. (A) Comparison of the proportion of different fatty acids recovered as ${ }^{13} \mathrm{CO} \mathrm{O}_{2}$ on breath under identical conditions (Delany et al. 2000). (B) The effect of consuming experimental diets with fatty acid compositions based on the typical pattern of fatty acid consumption in the UK (control); providing $9.6 \mathrm{~g} \alpha$-linolenic acid $(\alpha \mathrm{LNA}) / \mathrm{d}$ (high $\alpha \mathrm{LNA})$; providing $1.7 \mathrm{~g}$ EPA + DHA/d

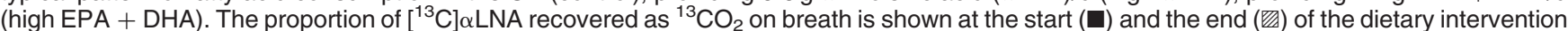
(Burdge et al. 2003). Values are means, with standard errors represented by vertical bars. 16: 0, Palmitic acid; 18: 0 , stearic acid; 18 : $1 n$-9, oleic acid; LA, linoleic acid.

$\beta$-oxidation in men compared with women (Burdge et al. 2002; Burdge \& Wootton, 2002). Comparison of the amount of ${ }^{13} \mathrm{C}$ recycled into SFA and MUFA with that incorporated by desaturation and elongation of $\alpha$ LNA into longer-chain PUFA in plasma over $21 \mathrm{~d}$ showed marked differences between men and women (Table 2). In men, the carbon recycling greatly exceeded conversion to longer-chain PUFA. In contrast, the amount of carbon recycled into SFA and MUFA in women was about $20 \%$ of that recovered in $n$-3 PUFA (Table 2). One overall implication of these findings is that the extent of partitioning of $\alpha$ LNA towards $\beta$-oxidation and carbon recycling may be an important control point in the regulation of the availability of $\alpha \mathrm{LNA}$ for conversion to longer-chain PUFA and that the relative partitioning between these metabolic fates differs markedly between men and women. This suggests that the extent of partitioning of $\alpha$ LNA towards $\beta$-oxidation may not simply reflect sex differences in muscle mass.

\section{The general pathway for conversion of $\alpha$-linolenic acid to longer-chain polyunsaturated fatty acids}

A pathway for the conversion of the essential fatty acids LA and $\alpha$ LNA to longer-chain PUFA has been described in rat liver (for a review, see Sprecher, 2002) and is summarised in Fig. 4. All reactions occur in the endoplasmic reticulum with the exception of the final reaction which results in the formation of DHA. Since both $n-6$ and $n-3$ PUFA are metabolised by the same desaturation-elongation pathway, there exists potential for competition between these two 
Table 2. Recycling of carbon from $\left[\mathrm{U}-{ }^{13} \mathrm{C}\right] \alpha$-linolenic acid and conversion to longer-chain polyunsaturated fatty acids in men and women (Data from Burdge \& Wootton, 2002, 2003)

\begin{tabular}{lcc}
\hline Fatty acid & \multicolumn{2}{c}{ AUC over $21 \mathrm{~d}(\mu \mathrm{mol} / \mathrm{l})$} \\
Wen & Women \\
\hline Palmitic acid $(16: 0)$ & 22 & 15 \\
Palmitoleic acid $(16: 1 n-7)$ & 3 & 3 \\
Stearic acid $(18: 0)$ & 6 & 5 \\
Oleic acid $(18: 1 n-9)$ & 7 & 4 \\
Total SFA + MUFA & 38 & 27 \\
EPA & $0 \cdot 2$ & 87 \\
DPA & $0 \cdot 2$ & 21 \\
DHA & $\mathrm{ND}$ & 34 \\
Total $n$-3 PUFA & $0 \cdot 4$ & 142 \\
SFA + MUFA: $n$-3 PUFA ratio & 95 & $0 \cdot 2$ \\
\hline
\end{tabular}

AUC, area under the curve; SFA, saturated fatty acids; DPA, docosapen taenoic acid; ND, not detected.

families of fatty acids. The initial conversion of $\alpha \mathrm{LNA}$ to $18: 4 n-3$ by the action of $\Delta 6$-desaturase is the rate-limiting reaction of the pathway. The affinity of $\Delta 6$-desaturase for $\alpha$ LNA is greater than for LA (Sprecher, 2002). However, the typically higher concentration of LA than $\alpha$ LNA in cellular pools results in greater conversion of $n-6$ PUFA. The introduction of a double bond at the $\Delta 6$ position is followed by the addition of $2 \mathrm{C}$ by elongase activity and then by desaturation at the $\Delta 5$ position by $\Delta 5$-desaturase to form EPA. DPA is synthesised from EPA by the addition of $2 \mathrm{C}$. The conversion of DPA to DHA has been a matter of controversy and two pathways have been suggested for this reaction. First, $\Delta 4$-desaturase activity has been suggested to be the primary mechanism for DHA synthesis (Infante \& Huszagh, 1998). However, others have demonstrated that the synthesis of DHA involves the formation of 24-carbon

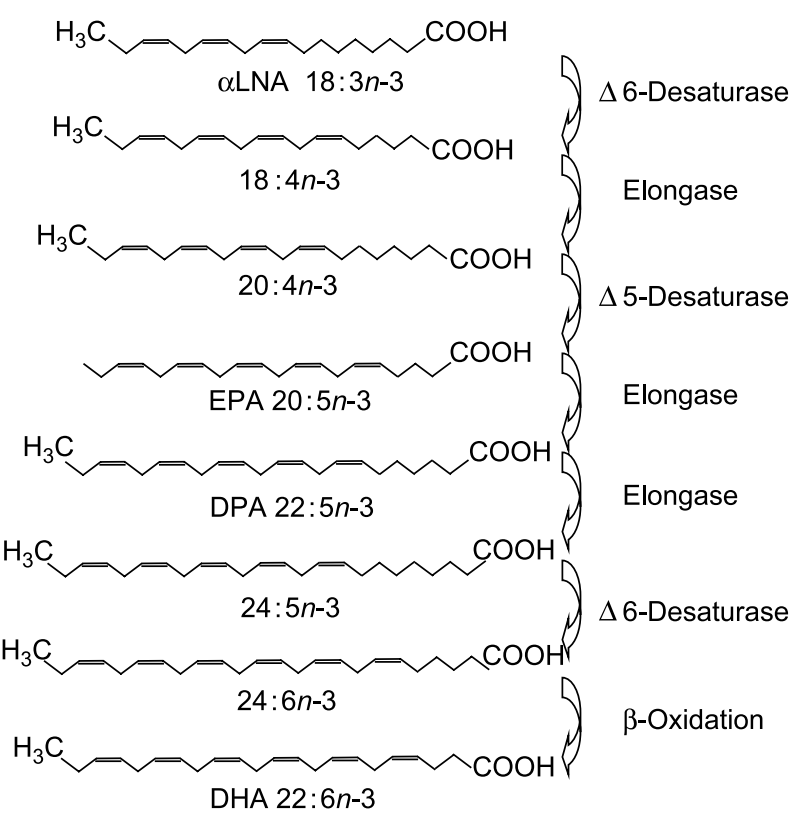

Fig. 4. The general pathway for conversion of $\alpha$-linolenic acid $(\alpha L N A)$ to longer-chain PUFA (Sprecher, 2002). DPA, docosapentaenoic acid. intermediates, a second desaturation at the $\Delta 6$ position and limited peroxisomal $\beta$-oxidation (Sprecher, 2002). Studies in which subcellular organelles were isolated and then recombined (Li et al. 2000) and reports of the action of the specific $\Delta 6$-desaturase inhibitor SC-26196 (Harmon et al. 2003) strongly support the second pathway. Furthermore, patients with peroxisome disorders such as Zellweger's syndrome have lower plasma DHA concentration, which is the result of a failure to convert DPA to DHA in the absence of an active peroxisomal $\beta$-oxidation pathway (Martinez, 2000 ). Thus the consensus pathway for the conversion of DPA to DHA is as follows: DPA is elongated to $24: 5 n-3$ which is desaturated at the $\Delta 6$-position by the action of $\Delta 6$-desaturase activity to form $24: 6 n$-3. It is unclear whether the same enzyme is responsible for desaturation of $\alpha$ LNA and $24: 5 n-3$ (Marzo et al. 1996; de Antueno et al. 2001; D'andrea et al. 2002). Then $24: 6 n-3$ is translocated from the endoplasmic reticulum to the peroxisome where the acyl chain is shorted by $2 \mathrm{C}$ by one cycle of the $\beta$ oxidation pathway to form DHA. DHA is then translocated back to the endoplasmic reticulum. Although the precise regulation of the translocation steps and limited $\beta$-oxidation is not known, it is possible that this represents a locus for metabolic regulation that facilitates the control of DHA synthesis independently from the preceding steps of the pathway.

The activity of the desaturation-elongation pathway in the liver is the most important in terms of supply of $\alpha \mathrm{LNA}$ metabolites to other tissues. However, expression of $\Delta 6$ and $\Delta 5$ desaturases has also been reported in human heart, brain, placenta, skeletal muscle, kidney, and pancreas (Cho et al. 1999). An active desaturation-elongation pathway has also been reported in immortalised human T cells (Jurkat cells), but not B cells (Marzo et al. 1995), and in sebaceous glands (Ge et al. 2003). Human epidermis appears to possess $\Delta 6$-desaturase, but not $\Delta 5$-desaturase activity (Chapkin et al. 1986). Whether the activity of the desaturation-elongation pathway contributes quantitatively to meeting the demands of these tissues for long-chain PUFA remains to be determined.

\section{$\alpha$-Linolenic acid conversion to longer-chain $\boldsymbol{n - 3}$ polyunsaturated fatty acids in human adults}

Current understanding of the extent to which man can convert $\alpha$ LNA to longer-chain PUFA is based on the findings of studies reporting the outcomes of chronic increases in intake of $\alpha$ LNA on concentrations of $n$-3 PUFA in plasma, cell and tissue lipid pools, and of shorter-term studies in which subjects consume a bolus of $\alpha$ LNA labelled with a stable isotope.

\section{Effects of chronically increased $\alpha$-linolenic acid consumption}

A number of studies have reported the effects of consuming increased amounts of $\alpha$ LNA, usually via consumption of oils with a high $\alpha$ LNA content or of products made with those oils (for example, spreads), on the fatty acid composition of plasma or cell lipids (Tables 3 and 4). These studies were conducted either in men or in mixed 

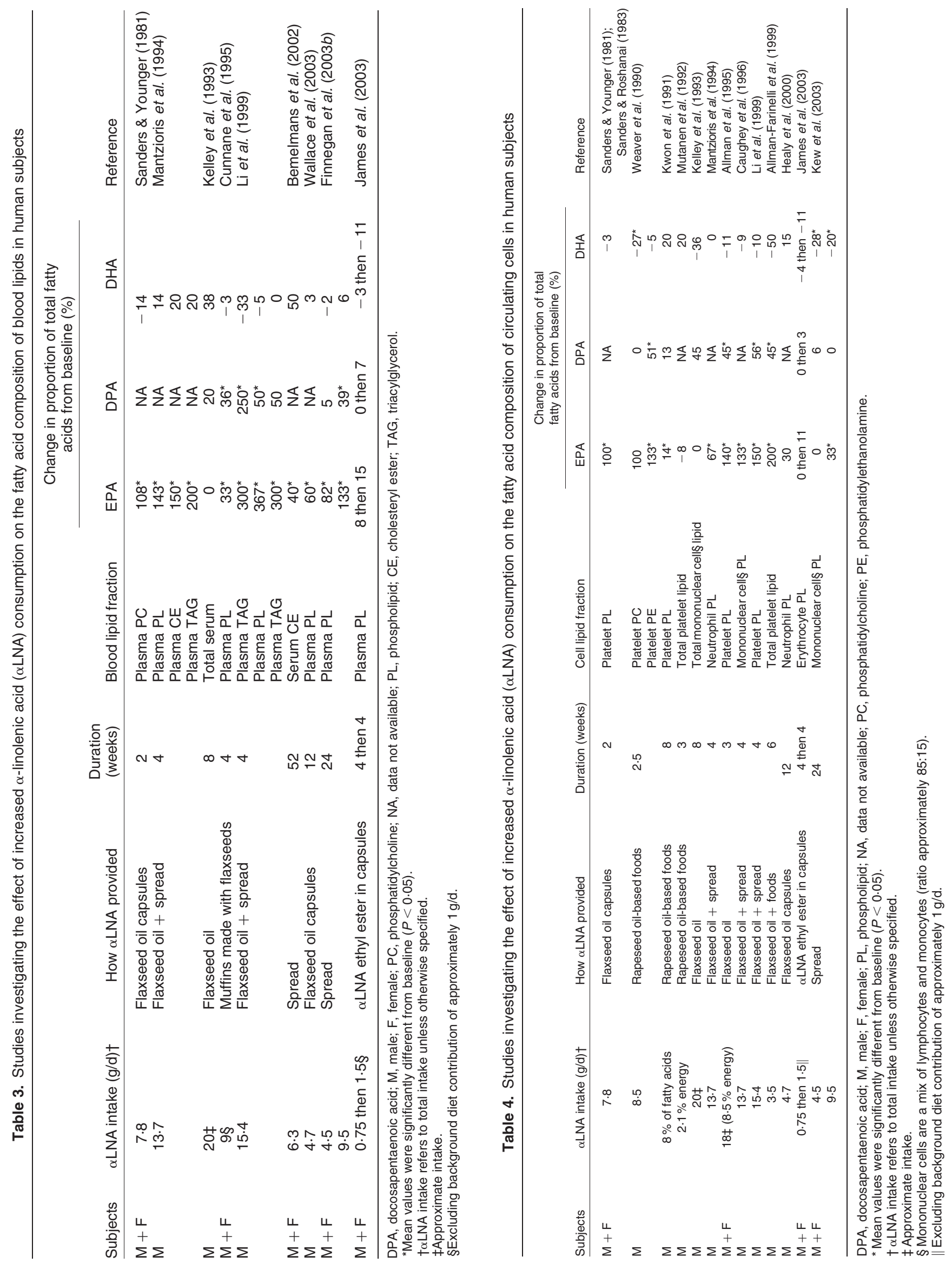
groups of men and women, used intakes of $\alpha$ LNA ranging from less than 1 to $20 \mathrm{~g} / \mathrm{d}$, and were of a few weeks' to many months' duration (Tables 3 and 4). Despite differences in the study design, physical form in which the $\alpha$ LNA was presented and the duration of the studies, overall they consistently demonstrate increased proportions of EPA in both plasma and cell lipids when $\alpha$ LNA intake is increased (Tables 3 and 4). The relationship between increased $\alpha$ LNA intake and increased EPA concentration in plasma phospholipids is a significant linear one ( $r$ 0.846; $P=0.004$; Fig. 5). The relationship for cell phospholipids is also likely to be linear, but there are insufficient data for a single cell type to allow this to be clearly identified at this stage. There is also some variation in the response between studies which might reflect differences in age and sex mix of the subjects studied, differences in the fatty acid content of the background diet, differences in the way in which $\alpha$ LNA was provided and differences in analytical procedures used.

Because of competition for metabolism between LA and $\alpha \mathrm{LNA}$, the LA content of the diet may influence conversion of $\alpha$ LNA to longer-chain derivatives. If this is so, then the EPA content of blood and cell lipids should be greater at a given intake of $\alpha$ LNA if LA intake is decreased. A study by Chan et al. (1993) demonstrated that this is indeed the case. Subjects consumed diets providing $7 \mathrm{~g} \alpha \mathrm{LNA} / \mathrm{d}$ for $18 \mathrm{~d}$ against a background of either 21 or $50 \mathrm{~g} \mathrm{LA} / \mathrm{d}$. The proportion of EPA was greater after the low- compared with the high-LA background in plasma PC $(0.8$ v. $0.3 \%$ of fatty acids), plasma phosphatidylethanolamine $(0.9$ v. $0.3 \%$ of fatty acids) and platelet PC (0.25 v. $0.1 \%$ of fatty acids).

Several studies also demonstrate increased proportions of DPA in plasma and cell lipids when $\alpha$ LNA consumption is increased (Tables 3 and 4). The studies also consistently demonstrate that increased consumption of $\alpha$ LNA does not result in increased proportions of DHA in plasma or cell lipids (Tables 3 and 4). Indeed many studies report a tendency for DHA to decline when $\alpha$ LNA consumption is markedly increased, although few studies have identified this as a statistically significant effect (Tables 3 and 4).

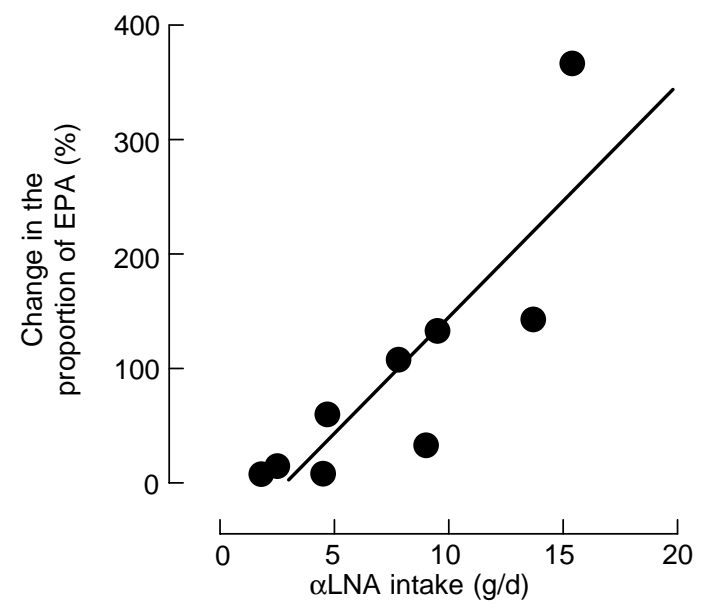

Fig. 5. The relationship between consumption of $\alpha$-linolenic acid $(\alpha$ LNA) and the change in the concentration of EPA in plasma phospholipids. Data are taken from references cited in Table 3.
Overall, these studies demonstrate that chronically increased consumption of $\alpha \mathrm{LNA}$ results in conversion to EPA resulting in increases in EPA concentration in plasma and cell pools, while the extent of conversion to DHA is insufficient to increase the concentration of this fatty acid.

\section{Estimates of $\alpha$-linolenic acid conversion from stable- isotope tracer studies}

A number of studies using $\alpha$ LNA labelled with either ${ }^{13} \mathrm{C}$ or ${ }^{2} \mathrm{H}$ have provided estimates of the extent of conversion to longer-chain PUFA in man. The advantages and limitations of these techniques have been reviewed (Emken, 2001). There remain unresolved issues regarding standardisation of quantification of data (particularly how conversion between fatty acids should be estimated), kinetic modelling, variation between subjects including age and sex, the method of administration of the labelled fatty acid, the duration of the study, the extent to which the background diet is controlled and the use of measurements of labelled fatty acids in blood (including which lipid pool should be measured) as a marker of fatty acid metabolism within tissues. Together these factors have resulted in considerable heterogeneity in the findings of such studies (Emken et al. 1994, 1999; Salem et al. 1999; Vermunt et al. 2000; Pawlosky et al. 2001, 2003a,b; Burdge et al. 2002, 2003; Burdge \& Wootton, 2002; Goyens et al. 2005; Hussein et al. 2005) (Table 5). This presents a considerable challenge to any attempt to reach a consensus view on $\alpha$ LNA metabolism in man. Nevertheless, at present there are no practical alternatives to these stable-isotope tracer techniques to study human $\alpha$ LNA metabolism in vivo.

The outcomes of stable-isotope tracer studies designed to investigate conversion of $\alpha$ LNA to longer-chain PUFA in man are summarised in Table 5. The general consensus of these studies is that the proportion of $\alpha$ LNA entering the desaturation-elongation pathway and converted to EPA and DPA is low. The extent of conversion of $\alpha$ LNA to DHA is even less clear (Table 5). The highest estimated fractional conversion is $4 \%$ (Emken et al. 1994), while most other studies have reported lower estimates of conversion (0.05\% or less) (Emken et al. 1999; Salem et al. 1999; Vermunt et al. 2000; Pawlosky et al. 2001, 2003a,b; Burdge et al. 2003; Goyens et al. 2005; Hussein et al. 2005) and one study failed to detect significant incorporation of stable isotope into DHA above background ${ }^{13} \mathrm{C}$ enrichment (Burdge et al. 2002).

Pawlosky et al. (2001) have suggested estimates for the efficiency of conversion of individual steps in the desaturation-elongation pathway from kinetic analysis based on the concentrations of individual ${ }^{2} \mathrm{H}$-labelled fatty acids in plasma from a mixed group of men and women consuming a beef-based diet. The findings of the study were that the efficiency of conversion of $\alpha$ LNA to EPA was $0.2 \%$, of EPA to DPA $65 \%$ and of DPA to DHA $37 \%$. Thus, the overall efficiency of conversion from $\alpha \mathrm{LNA}$ is $0.2 \%$ to EPA, $0.13 \%$ to DPA and $0.05 \%$ to DHA. This is in general agreement with the other studies summarised in Table 5 and with the assumption that the first reaction catalysed by $\Delta 6$-desaturase is the rate-limiting step of the pathway. 


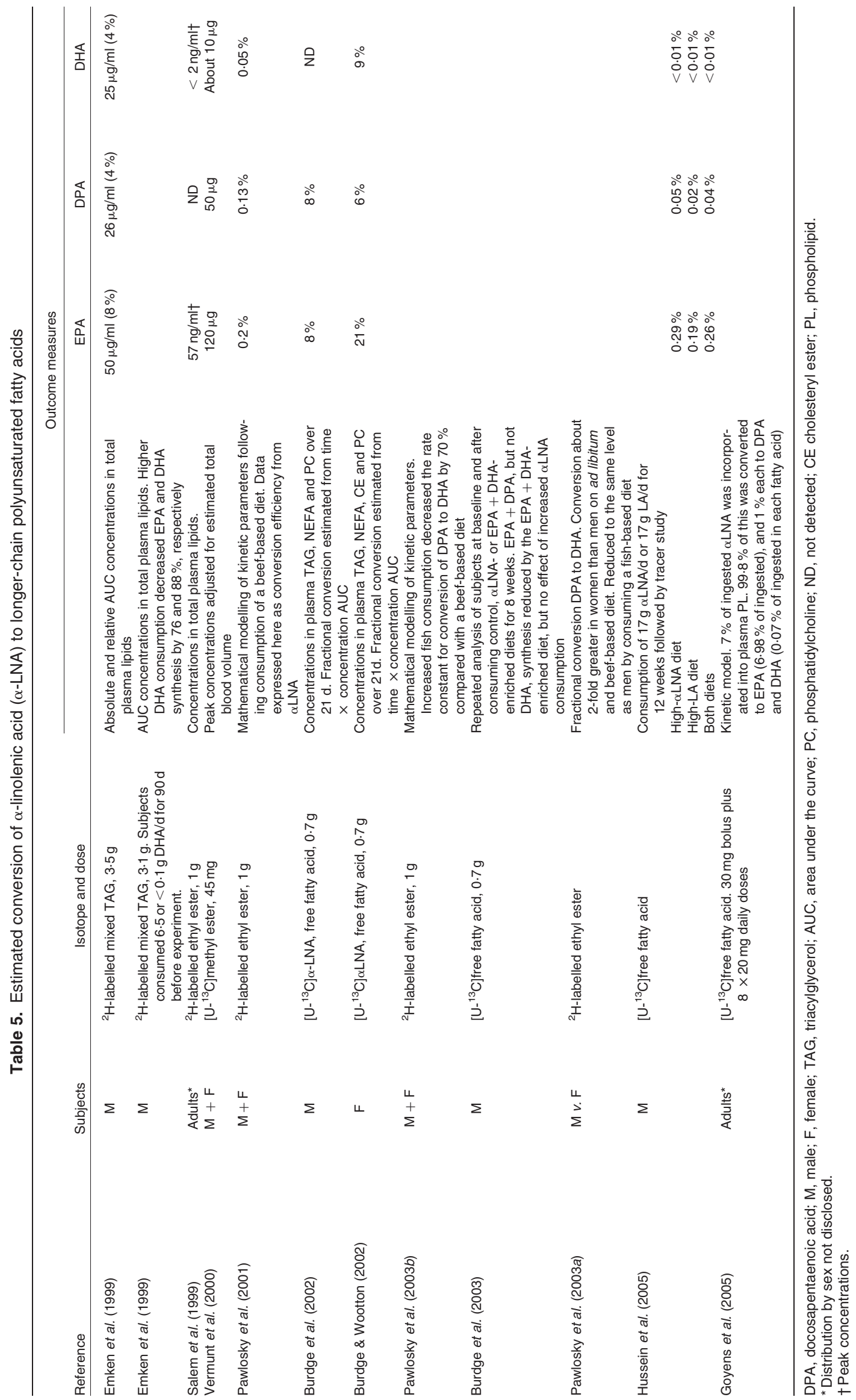


Several studies have reported the effects of modifications to the background diet on the extent of $\alpha$ LNA conversion to long-chain $n$-3 PUFA determined using stable-isotope tracers. The effect of increased consumption of EPA + DHA or DHA alone on this process is of interest because of the potential for feedback inhibition of this pathway. Emken et al. (1999) compared the effect of consuming diets either containing $<0.1 \mathrm{~g}$ DHA/d or supplemented with $6.5 \mathrm{~g}$ purified DHA/d. There was a $76 \%$ reduction in EPA synthesis and an $88 \%$ reduction in DHA synthesis in the group receiving the DHA supplement. Others have reported a decrease in the conversion efficiency of DPA to DHA following the consumption of a fish-based diet (containing $\mathrm{EPA}+\mathrm{DHA}$ ) compared with a beef-based diet in a mixed group of men and women (Pawlosky et al. 2003b). However, when the fractional conversion of DPA to DHA was calculated separately for men and women, the decrease in DHA synthesis as a result of consuming a fish-based diet was only found in the female subjects (Pawlosky et al. $2003 a$ ). Consumption of $1.6 \mathrm{~g} \mathrm{EPA}+\mathrm{DHA} / \mathrm{d}$ for 8 weeks decreased EPA and DPA, but not DHA, synthesis when $\alpha$ LNA conversion was compared before and after the intervention in the same individuals (Burdge et al. 2003). These studies indicate that increased consumption of longchain $n$-3 PUFA acts to down regulate their synthesis from $\alpha \mathrm{LNA}$, possibly by activation of peroxisomal proliferatoractivated receptor- $\alpha$ leading to inhibition of $\Delta 6$-desaturase transcription (Tang et al. 2003). One recent study showed that consuming either $17 \mathrm{~g} \mathrm{LA} / \mathrm{d}$ or $17 \mathrm{~g} \alpha \mathrm{LNA} / \mathrm{d}$ inhibited the conversion of the alternate series of fatty acids (Hussein et al. 2005). In contrast, Vermunt et al. (2000) found that increased $\alpha$ LNA intake $(8 \mathrm{~g} / \mathrm{d})$ decreased EPA, DPA and DHA synthesis, although others have not found this (Burdge et al. 2003).

Overall, substantial increases in the intakes of individual fatty acids are able to modify the conversion of $\alpha \mathrm{LNA}$, although there are inconsistencies in the magnitude of these effects between reports.

Since there is a positive linear relationship between the amount of $\alpha$ LNA consumed and the change in plasma phospholipid EPA concentration (Fig. 5), it is possible to evaluate the accuracy of the estimates of $\alpha$ LNA conversion provided by studies using stable-isotope tracers. It is assumed that doubling the provision of EPA will increase its concentration in plasma phospholipid by $100 \%$. The daily intake of EPA in the UK is about $0.06 \mathrm{~g}$ (Ministry of Agriculture, Fisheries \& Food, 1997). Thus a further 0.06 g would be required to double the concentration of EPA in the circulation. In order to make a direct comparison between pools, estimated fractional conversion of $\alpha$ LNA based upon the measurement of ${ }^{13} \mathrm{C}$ incorporation into plasma phospholipid will be used, which is about $5 \%$ in men (Burdge et al. 2002). In the UK, where this study was conducted, men consume about $1.5 \mathrm{~g} \alpha \mathrm{LNA} / \mathrm{d}$. Partitioning towards $\beta$-oxidation removes about $33 \%$ of $\alpha$ LNA from the pool derived from the diet which is available for conversion, leaving $1.0 \mathrm{~g}$. As there are no estimates for the fractional partitioning of $\alpha$ LNA into storage or membrane pools it will be assumed that all of the remaining $\alpha$ LNA is available for conversion, which obviously results in an overestimation of the synthesis of EPA. If it is assumed that about $5 \%$ is converted to EPA, then $1 \mathrm{~g} \alpha \mathrm{LNA}$ will provide $0.05 \mathrm{~g}$ EPA, which would almost double the provision of EPA. Thus, the consumption of $1 \mathrm{~g}$ of $\alpha \mathrm{LNA}$ above the background diet would be expected to double the concentration of EPA in the circulation. Others have suggested that, based on kinetic models, $0.2 \%$ of $\alpha$ LNA is converted to EPA (Pawlosky et al. 2001), which would provide $0.002 \mathrm{~g}$ EPA, which would mean that $300 \mathrm{~g} \alpha \mathrm{LNA}$ would need to be consumed in order to provide an additional $0.06 \mathrm{~g}$ above the intake in the background diet. The data in Fig. 5 show that $5 \mathrm{~g}$ is required to double the provision of EPA, and so neither of these estimates of $\alpha$ LNA conversion based upon stable-isotope tracer studies is entirely correct. There are two possible explanations. First, the true level of conversion lies between the two experimental values and is in the order of $2 \%$ if it is assumed that $1.7 \mathrm{~g}$ (i.e. $33 \%$ of $5 \mathrm{~g}$ ) is lost in $\beta$-oxidation and all of the remaining $\alpha$ LNA is available for desaturation and elongation. This is unlikely to be true. Second, if the estimate of $5 \%$ conversion was correct, then the pool available for conversion must be less than $1 \mathrm{~g}$ by a factor of 5. One possible explanation is that $80 \%$ of $\alpha$ LNA which is ingested and is not used to produce energy enters pools which are not available for conversion to longer-chain PUFA, such as storage pools in adipose tissue or structural pools in cell membranes. If so, the pool of $\alpha$ LNA available for conversion would be $0.2 \mathrm{~g}$ for each $1 \mathrm{~g}$ consumed. For example, if $5 \mathrm{~g} \alpha \mathrm{LNA}$ are consumed, $\beta$-oxidation would account for $1.7 \mathrm{~g}$, and $2.3 \mathrm{~g}$ would enter storage or membrane pools, leaving $1.0 \mathrm{~g}$ which would be available for conversion. Of this, $5 \%$ would be used to provide $0.05 \mathrm{~g}$ EPA. The proportion of ingested $\alpha$ LNA incorporated into pools not used for conversion or $\beta$-oxidation, presumably storage or cell membranes, is comparable with the estimated upper range $(57 \%)$ of incorporation of $\left[{ }^{13} \mathrm{C}\right] \alpha$ LNA into total adipose tissue (McCloy et al. 2004). The calculations presented here are obviously an oversimplification of the processes which determine the extent to which dietary $\alpha$ LNA is converted to EPA. However, these estimates do suggest a level of fractional conversion of $\alpha$ LNA to EPA, which can explain the data from dietary intervention studies, and are consistent with the findings of at least some of the stable-isotope tracer studies.

\section{$\alpha$-Linolenic acid metabolism: sex differences}

The majority of investigations of $\alpha$ LNA metabolism in human subjects have focused on groups of relatively young healthy individuals, either men or mixed groups of men and women. There is relatively little information regarding the effects of sex on this process. Two reports have specifically studied $\alpha$ LNA conversion in women of reproductive age. Burdge \& Wootton (2002) showed that conversion of $\alpha$ LNA to EPA and DHA in women aged about 28 years was substantially greater $(2 \cdot 5$-fold and $>200$-fold, respectively) than in a comparable study of men of similar age (Burdge et al. 2002) (Table 5). This finding is strongly supported by kinetic analysis, which showed that the rate-constant coefficient for the conversion of DPA to DHA was approximately 4-fold greater in women compared with men (Pawlosky et al. 2003a) (Table 5). This may reflect a greater availability of $\alpha \mathrm{LNA}$ for conversion in women than 
in men that may perhaps, in part, be due to lower partitioning towards $\beta$-oxidation. However, since the rateconstant coefficient for the conversion of DPA to DHA was greater in women than men (Pawlosky et al. 2003a), it is likely that there is a sex-related difference in the activity of the desaturation-elongation pathway.

One possible explanation for the greater synthesis of EPA and DHA from $\alpha$ LNA in women compared with men is the action of oestrogen. DHA synthesis was almost 3-fold greater in women using an oral contraceptive pill containing $17 \alpha$-ethylnyloestradiol than in those who did not (Burdge \& Wootton, 2002). The suggestion that oestrogen may increase the activity of the desaturation-elongation pathway is consistent with the finding that oestrogen-based hormone replacement therapy in postmenopausal women resulted in greater plasma dihomo- $\gamma$-linolenic and arachidonic acid concentrations than before treatment (Ottosson et al. 1984). Furthermore, DHA concentration in the plasma cholesteryl ester fraction has recently been shown to be greater in women $(0.53 \%$ total fatty acids) compared with men ( $0.48 \%$ total fatty acids) consuming diets controlled for energy and $\alpha$ LNA content, although DHA is a minor component of this plasma lipid pool (Giltay et al. 2004b). Interestingly, administration of $17 \alpha$-ethylnyloestradiol to male to female transsexuals increased the concentration of DHA in plasma cholesteryl esters by $42 \%$ which is in agreement with the effects of oral contraceptive pill use on $\alpha$ LNA conversion (Burdge \& Wootton, 2002). Conversely, testosterone decreased DHA concentration by $22 \%$ in female to male transsexuals (Giltay et al. 2004b). Hormone replacement therapy in postmenopausal women also increased plasma cholesteryl ester arachidonic acid and DHA concentrations (Giltay et al. 2004a). Our own data (L Bakewell, PC Calder and GC Burdge, unpublished results) show that women (aged 18 to 35 years) have a $50 \%$ higher concentration of DHA in plasma PC compared with men of similar age and BMI $\left(>20\right.$ and $\left.<30 \mathrm{~kg} / \mathrm{m}^{2}\right)$ (Fig. 6). Together these data strongly support the suggestion that sex hormones, in particular oestrogen, regulate the activity of the desaturation-elongation pathway in man.

One possible biological role for greater capacity for $\alpha$ LNA conversion in women may be in meeting the demands of the fetus and neonate for DHA. The developing human fetus assimilates at least $400 \mathrm{mg}$ DHA per week during the third trimester (Lauritzen et al. 2001). Since this estimate reflects only brain, adipose tissue and liver requirements, the overall demands for DHA are likely to be substantially greater. Desaturase activities in the developing human liver appear to be lower than in adults (de Gomez Dumm \& Brenner, 1975; Sauerwald et al. 1977; Poisson et al. 1993; Salem et al. 1996; Carnielli et al. 1996), and so the capacity of the fetus and neonate to satisfy their demands for DHA may be limited. Thus, assimilation of DHA by the fetus has to be met primarily by supply of DHA by the mother. In pregnant women, plasma PC DHA concentration increases by approximately $33 \%$ between 16 weeks $(170 \mu \mathrm{mol} / \mathrm{l})$ and 40 weeks $(230 \mu \mathrm{mol} / \mathrm{l})$ gestation (Postle et al. 1995). When the increase in maternal blood volume during pregnancy is taken into account (Gregersen \& Rawson, 1959), in women there is an overall doubling of DHA in the circulation. Since circulating oestrogen

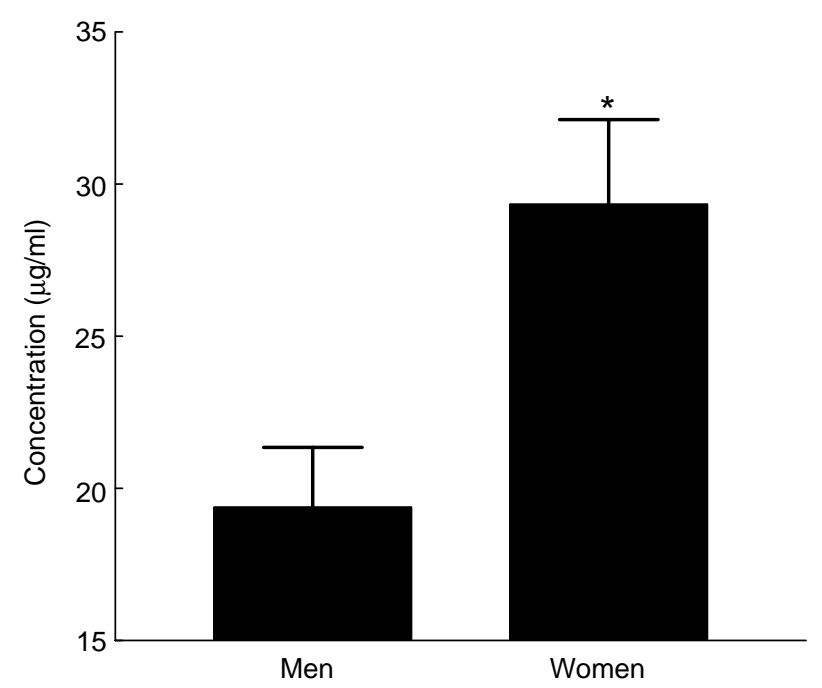

Fig. 6. The concentration of DHA in plasma phosphatidylcholine in men and women consuming their habitual diets. Values are means, with standard errors represented by vertical bars. * Mean value was significantly different from that for men $(P=0.02)$ ( $\mathrm{L}$ Bakewell, PC Calder and GC Burdge, unpublished results).

concentration rises during pregnancy due to synthesis and secretion by the placenta, one possibility is that $\alpha \mathrm{LNA}$ conversion may increase during gestation. This is supported by studies in rats that indicate that the increased plasma PC DHA concentration during pregnancy is the result of physiological adaptations to hepatic phospholipid (Burdge et al. 1994) and oLNA (Larque et al. 2003) metabolism. If true in women, one implication would be that the $50 \%$ variation between pregnant women in plasma PC DHA concentration at term (Postle et al. 1995) may reflect differences in $\alpha$ LNA metabolism in addition to any dietary effects. This may influence the supply of DHA to the fetus and, in turn, the development and function of neural tissues.

Consumption of $10.7 \mathrm{~g} \alpha \mathrm{LNA} / \mathrm{d}$ by lactating women increased maternal plasma, erythrocyte and breast-milk $\alpha$ LNA concentration (Francois et al. 2003). The effect on breast-milk EPA and DPA concentrations is less clear, as the difference between baseline DPA concentration $(0.19 \pm 0.05 \%)$ and that after 4 weeks of supplementation $(0.17 \pm 0.02 \%)$ does not support the claim that the DPA content of milk increased over time (Francois et al. 2003). Increased consumption of $\alpha$ LNA did not alter breast-milk DHA concentration (Francois et al. 2003). This is consistent with the finding that newly synthesised arachidonic acid is a minor component of the arachidonic acid content of breast milk (Del Prado et al. 2001). One interpretation is that the incorporation of PUFA into milk may be dependent upon mobilisation of stores accumulated in adipose tissue before conception and during pregnancy. If so, this emphasises the importance of adequate nutrition of women both before and during pregnancy. Furthermore, since prolactin suppresses oestrogen activity, the activity of the desaturationelongation pathway may be down regulated in lactating compared with non-pregnant and pregnant women, and so these results do not exclude the possibility of increased DHA synthesis during pregnancy. 


\section{Conversion of $\alpha$-linolenic acid to longer-chain polyunsaturated fatty acids: the legacy of our ancestors?}

The function of the brain is arguably the major distinguishing characteristic of Homo sapiens. The human brain weighs about $1300 \mathrm{~g}$, of which $60 \%$ is lipid. Longchain PUFA are critically important for neurological development and function, in particular DHA, and deficit in the DHA content of neural membranes is associated with impaired function (Fernstrom, 1999). Thus the interaction between the availability of long-chain PUFA, in particular DHA, and the development of the brain is likely to have been a critical process in the evolution of $H$. sapiens. The growth in both size and functional capacity which accompanied the evolution of $H$. sapiens from our common ancestor with the chimpanzees 5.8-7.1 million years ago (Hacia, 2001) would have required an increase in the availability of DHA to support the increased synthesis of brain tissues during development and to replenish the turnover of neural membrane phospholipids. The level of DHA in the meat of species living on the African savanna, although greater than domesticated species, is relatively low (Broadhurst et al. 2002) and the hunting skills required too great for this to be a major source of DHA to support the early evolution of the hominid brain (Muskiet et al. 2004). An alternative theory of the ancestral hunter-gatherer which emphasises the role of long-chain PUFA in the evolution of the brain suggests that hominids evolved along the margins of lakes and rivers, and along the seashore where fish provided a richer source of DHA than would have been obtained by a hunter-gatherer lifestyle (Broadhurst et al. 2002; Gibbons, 2002a; Muskiet et al. 2004). This is supported by the relatively large numbers of remains of early hominids and of their tools at Lake Turkana in the East African Rift Valley (now Kenya), in the Southern African Cape and in the Central African Chad Basin (Gibbons, 2002b). Furthermore, when early humans left Africa, they did so along a coastal route (Macaulay et al. 2005). One interpretation is that evolution of the human brain may have occurred in the presence of an adequate dietary supply of preformed DHA, and that there was little need for synthesis of DHA from $\alpha$ LNA. Furthermore, experiments in animal models suggest that recycling of DHA in cell membranes of the brain and the retina is highly efficient (Wiegand et al. 1991; Chang et al. 1999). In rats, $97 \%$ of DHA in the brain is derived from the recycling of DHA from membrane sources (Chang et al. 1999). If this is also found in human adults, this suggests that the actual daily requirements for DHA to replenish neural membranes may be very small, and so could be provided by relatively low dietary intakes. In the context of the evolution of the brain, such adaptation would tend to buffer its function against variations in the intake of DHA from the diet. The development of the brain represents the period of greatest sensitivity to deficits in supply of DHA. Since desaturase activities in fetal liver are unlikely to satisfy demands for DHA (Salem et al. 1996), the developing fetal brain is highly dependent upon a supply of preformed DHA from the mother. In this context, the capacity to increase maternal DHA synthesis by the action of oestrogen may be of particular importance in ensuring a supply of DHA to the fetus. Speculatively, this ability may have evolved to protect the developing fetal brain from a deficit in DHA accumulation, a risk which would be substantially greater if supply of DHA from the maternal diet was the sole source of DHA for supply to the fetus. Furthermore, accumulation of DHA into adipose tissue during the third trimester is about 10-fold greater $(380 \mathrm{mg}$ / week) than into the fetal brain $(35 \mathrm{mg} /$ week) (Clandinin et al. 1981). This suggests that one of the reasons why man (Poissonnet et al. 1984), unlike other primates (Adolph \& Heggeness, 1971; Lewis et al. 1983), has evolved the capacity to accumulate adipose stores in late gestation may be to provide a nutritional buffer during the transition from placental to oral supply (Kuzawa, 1998; Correia et al. 2004), thus preventing a deficit in DHA. This store is likely to depend upon supply of preformed DHA from the mother.

Overall, the capacity of modern man to convert $\alpha$ LNA to longer-chain PUFA, in particular DHA, appears to be consistent with our evolutionary past and the fatty acid content of our ancestral diet. This is reflected in differences in the efficiency of conversion of $\alpha$ LNA to DHA between men and women. In women, capacity to up regulate may be important for protecting the development of the fetal brain against deficit in DHA accumulation during pregnancy. The contrastingly low level of DHA synthesis in men may reflect the activity of recycling mechanisms that may limit the demands of neural tissue for DHA.

\section{$\alpha$-Linolenic acid and human health-related outcomes \\ Long-chain n-3 polyunsaturated fatty acids and human health}

Studies of disease incidence in native Inuit populations in Greenland, Canada and Alaska identified less cardiovascular and inflammatory disease than expected (Dyerberg et al. 1978; Kromann \& Green, 1980; Bjerregaard \& Dyerberg, 1988; Newman et al. 1993). This has been attributed to the very high dietary intake of long-chain $n-3$ PUFA among these populations (Bang et al. 1976). Epidemiological studies in Western Europe, the USA and Japan indicate decreased risk of CVD (for references, see Bucher et al. 2002; Kris-Etherton et al. 2002; Calder, 2004a; He et al. 2004) and inflammation (Shoda et al. 1996; Pischon et al. 2003; Lopez-Garcia et al. 2004) with increasing habitual consumption of fish, oily fish, or longchain $n$-3 PUFA. Supplementation studies with long-chain $n$-3 PUFA, usually as fish oil, have demonstrated beneficial impacts on a multitude of cardiovascular risk factors including fasting TAG concentrations (for reviews, see Harris, 1996; Roche \& Gibney, 1999), postprandial lipaemia (for a review, see Williams, 1997), blood pressure (for a meta-analysis, see Geleijnse et al. 2002), platelet aggregation (Sanders et al. 1981; Goodnight et al. 1981; von Schacky et al. 1985), blood coagulation and fibrinolysis (see British Nutrition Foundation, 1992), heart rate variability (Christensen et al. 1996, 2001), cardiac arrhythmias (Schrepf et al. 2004), vascular reactivity (Chin et al. 1993; McVeigh et al. 1994; Goode et al. 1997; Tagawa et al. 1999), and inflammation (for reviews, see Calder, 2001, 2002, 2003, 2005). Paradoxically there are reports that longchain $n-3$ PUFA increase the susceptibility of LDL to 
oxidation ex vivo (Suzukawa et al. 1995; Sorensen et al. 1998; Finnegan et al. 2003b), which, if it occurred in vivo, would be a deleterious, pro-atherogenic effect. Long-chain n-3 PUFA also affect immune function (for reviews, see Calder, 2001; Calder et al. 2002). If the effects of long-chain $n$-3 PUFA are representative of general effects of this class of fatty acids, then $\alpha$ LNA too could beneficially affect a range of cardiovascular risk factors and so could lower the risk of CVD in particular, but also inflammatory, and perhaps other, conditions. Alternatively through conversion to its longer-chain, more unsaturated derivatives which are found in fish oil, $\alpha$ LNA could exert the same health benefits ascribed to EPA and DHA. This has become an attractive notion because there are more sources of $\alpha$ LNA (nuts, seeds, vegetable oils) than of long-chain $n$-3 PUFA; $\alpha$ LNArich oils are readily available, inexpensive and sustainable; $\alpha$ LNA-rich oils are more easily incorporated into existing foodstuffs (spreads, cooking oils, cakes, biscuits, snacks etc) than are fish oils, thus representing less of a challenge to food technologists; and high amounts of $\alpha$ LNA do not affect the taste, smell and shelf life of foodstuffs in the same way that inclusion of high amounts of long-chain $n$ - 3 PUFA can and so are more attractive to food producers, food retailers and consumers. In addition, the lower propensity of $\alpha \mathrm{LNA}$ to free radical attack, compared with EPA and DHA, means that the risk of increased oxidative damage to lipoproteins such as LDL and to cell membranes is much lower. Finally, the view that the current intake of the $n$ - 6 PUFA LA is too high (Simopoulos, 2001; Lands, 2003) and increases the risk of thrombotic, inflammatory and allergic sequelae, provides an opportunity for $\alpha \mathrm{LNA}$ to decrease disease risk as a result of being a replacement in the diet for LA. For these reasons there has been significant interest in the effects of dietary $\alpha$ LNA intake on CVD and on its risk factors.

\section{$\alpha$-Linolenic acid and cardiovascular disease}

\section{Epidemiological associations}

Several studies report a protective effect of $\alpha$ LNA towards CVD. A population-based case-control study in Costa Rica reported that high adipose tissue $\alpha \mathrm{LNA}$ content, a marker for intake, was associated with lower risk of myocardial infarction (Baylin et al. 2003). Dietary aLNA intake was significantly inversely associated with mortality from CHD in the Multiple Risk Factor Intervention Trial (Dolecek, 1992). The highest quintile of $\alpha$ LNA intake $(1.36 \mathrm{~g} / \mathrm{d})$ was associated with $45 \%$ fewer coronary deaths in women compared with the lowest quintile $(0.71 \mathrm{~g} / \mathrm{d})$ ( $\mathrm{Hu}$ et al. 1999). Dietary $\alpha$ LNA intake was inversely associated with risk of myocardial infarction among men (Ascherio et al. 1996); there was a relative risk of 0.41 for each $1 \%$ increase in energy intake as $\alpha$ LNA. In a study of over 4400 men and women the highest quintile of $\alpha$ LNA intake $(1 \cdot 1 \mathrm{~g} / \mathrm{d})$ was associated with $40 \%$ lower mortality from coronary artery disease compared with the lowest quintile of intake $(0.5 \mathrm{~g} / \mathrm{d})$ (Djousse et al. 2001). In addition, dietary $\alpha$ LNA intake was inversely related to carotid atherosclerosis (Djousse et al. 2003) and to calcified atherosclerotic plaque in the coronary arteries (Djousse et al. 2005). In contrast to these findings, other epidemiological studies found no association between $\alpha$ LNA intake and CHD risk (Simon et al. 1995; Oomen et al. 2001) or mortality (Pietinen et al. 1997; Oomen et al. 2001). A recent meta-analysis of five prospective cohort studies (Dolecek, 1992; Ascherio et al. 1996; Pietinen et al. 1997; Hu et al. 1999; Oomen et al. 2001) concluded that high $\alpha$ LNA intake is associated with decreased risk of fatal CHD (Brouwer et al. 2004).

\section{Intervention studies}

The well-known Lyon Heart Study reported a substantial reduction in coronary events and deaths among myocardial infarction survivors following a Mediterranean-style diet which included an $\alpha$ LNA-rich margarine providing $1.5 \mathrm{~g}$ $\alpha \mathrm{LNA} / \mathrm{d}$ (de Lorgeril et al. 1994). However, this intervention also involved several other dietary changes and so the contribution, if any, of increased $\alpha$ LNA intake to the positive outcomes cannot be identified.

\section{$\alpha$-Linolenic acid and cardiovascular risk factors}

\section{Blood lipids}

A number of studies have investigated the effect of increased $\alpha$ LNA consumption on blood cholesterol, LDL and HDL concentrations (Table 6). While some of these studies report little effect of $\alpha \mathrm{LNA}$ intervention, several indicate that $\alpha \mathrm{LNA}$ is similar to LA with respect to blood cholesterol concentration (Kestin et al. 1990; Chan et al. 1991; Mantzioris et al. 1994; Arjmandi et al. 1998; Pang et al. 1998; Sodergren et al. 2001; Bemelmans et al. 2002; Finnegan et al. 2003b; Zhao et al. 2004). Likewise some of these studies indicate similar effects of $\alpha$ LNA and LA on LDL- and HDL-cholesterol concentrations (Kestin et al. 1990; Chan et al. 1991; Arjmandi et al. 1998; Sodergren et al. 2001; Bemelmans et al. 2002; Finnegan et al. 2003b; Zhao et al. 2004). However, two studies (Mantzioris et al. 1994; Pang et al. 1998) suggest that $\alpha$ LNA is not as effective as LA in lowering LDL-cholesterol concentrations. Furthermore, studies reporting that $\alpha$ LNA decreased HDL concentration (Nestel et al. 1997; Rallidis et al. 2003) did not see this effect with LA, while Bemelmans et al. (2002) found that HDL concentration was significantly lower (by $4 \%$ or $0.05 \mathrm{~mm}$ ) after $\alpha$ LNA than after LA. Taken together these data would suggest that, while $\alpha$ LNA is cholesteroland LDL-lowering, it is less effective than LA and that $\alpha$ LNA, unlike LA, may decrease HDL concentration.

Studies investigating the effect of $\alpha$ LNA on fasting plasma TAG concentrations are contradictory, with most reporting no change from baseline, several reporting an increase or a tendency to an increase, and two reporting a decrease (for references, see Table 6). These differences in outcome may relate to the fat content of the background diet, to habitual dietary fat composition, to whether subjects were placed on a standardised diet before the $\alpha \mathrm{LNA}$ intervention, to the amount of $\alpha$ LNA and of other fatty acids supplied, and to the degree of triacylglycerolaemia at baseline. It is interesting that the two studies reporting decreased plasma TAG concentrations used very high $\alpha$ LNA intakes (Singer et al. 1986; Zhao et al. 2004). Some studies permit the effect of $\alpha$ LNA on fasting TAG 


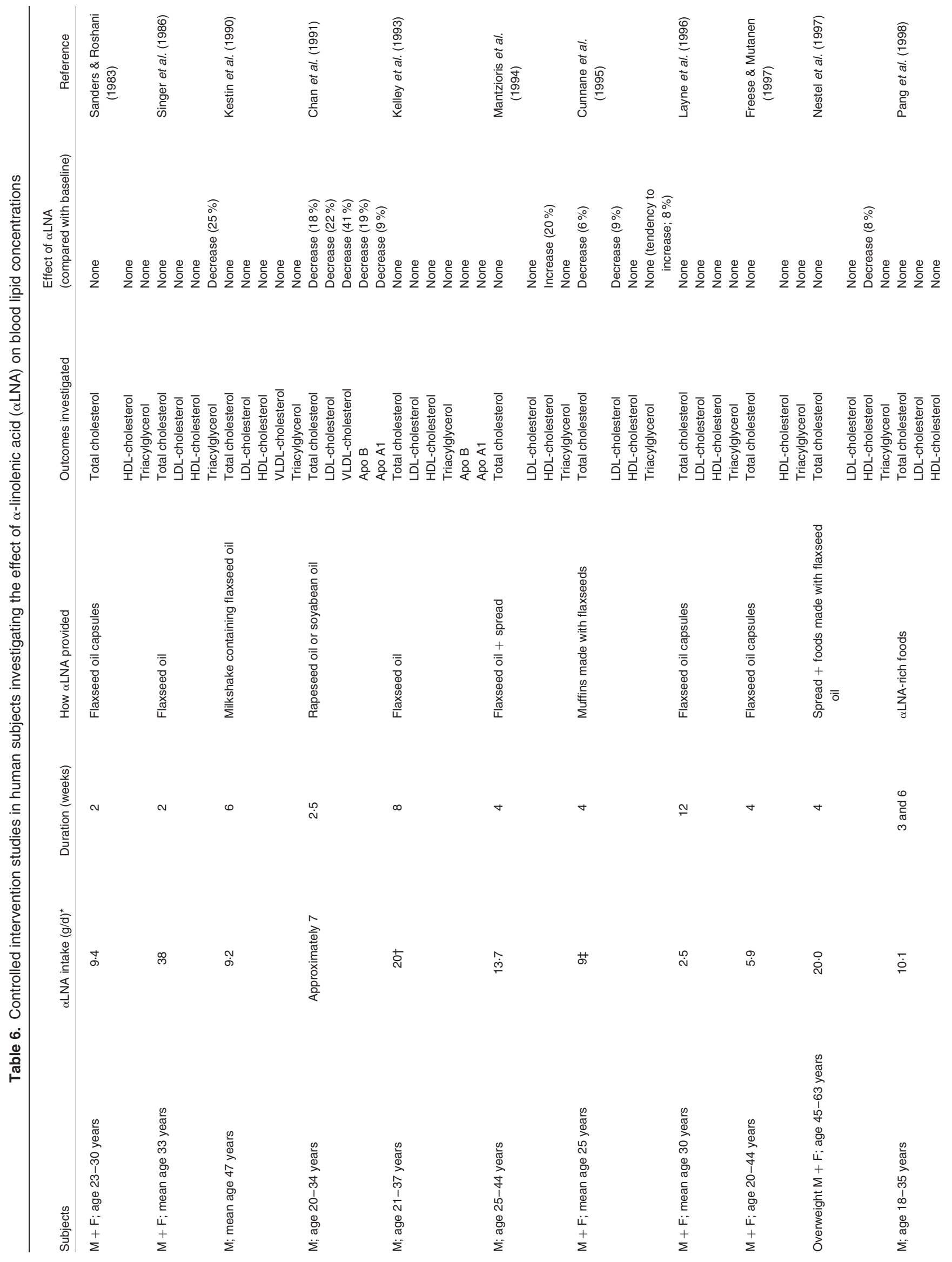




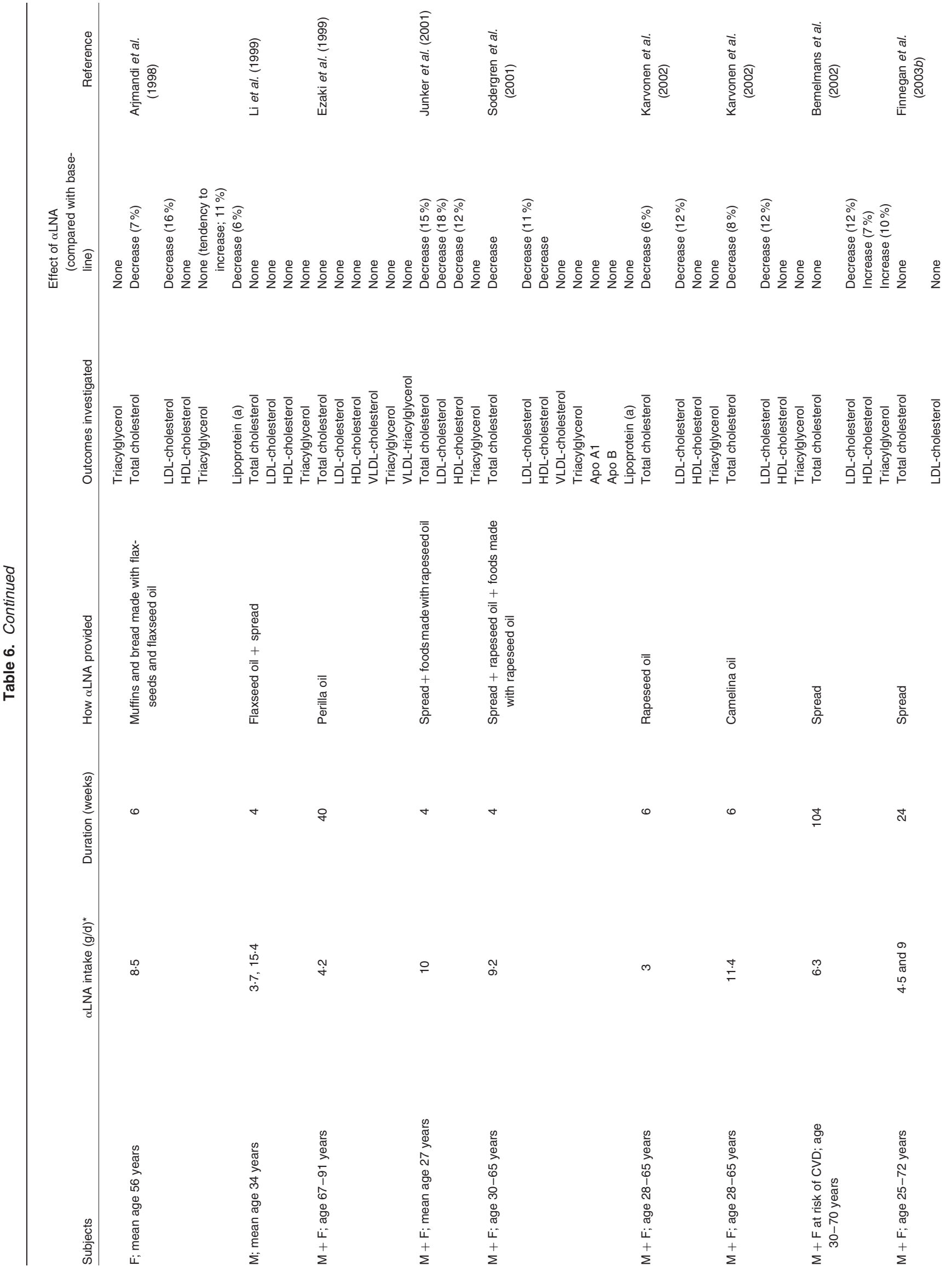




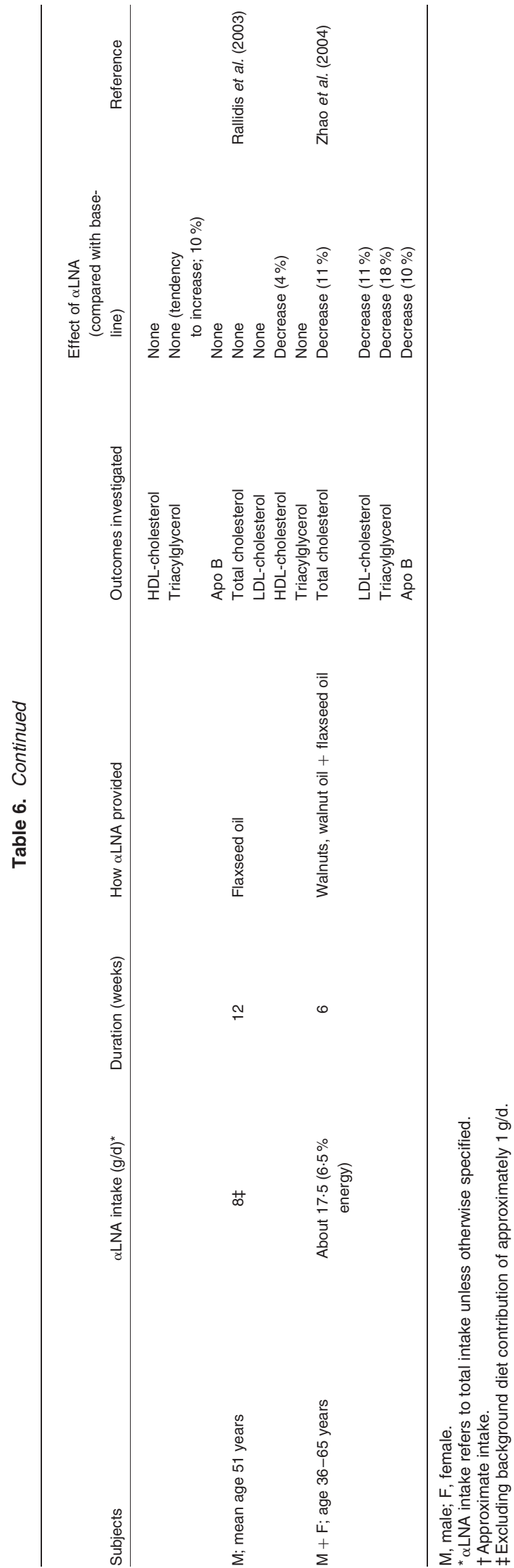

concentrations to be directly compared with that of LA. Kestin et al. (1990), Nestel et al. (1997), Pang et al. (1998), Rallidis et al. (2003) and Zhao et al. (2004) found that the effects of a high- $\alpha$ LNA diet were not different from those of an LA-rich diet. However, Arjmandi et al. (1998) and Finnegan et al. (2003b), who found that $\alpha$ LNA tended to increase TAG concentration, did not see this effect with a high-LA diet, while Bemelmans et al. (2002) reported that plasma TAG concentration was significantly higher $(12 \%$ or $0.24 \mathrm{~mm}$ ) after $\alpha$ LNA than after LA. These studies are suggestive that $\alpha$ LNA has a TAG-raising effect compared with LA.

\section{Postprandial lipaemia}

Lichtenstein et al. (1993) reported no differences in the postprandial TAG response to a test meal in subjects who consumed diets rich in rapeseed, maize or olive oils. More recently, Finnegan et al. (2003b) found no effect of diets containing 4.5 or $9 \mathrm{~g} \alpha \mathrm{LNA} / \mathrm{d}$ on the postprandial TAG response to a test meal, compared with study entry or with an LA-rich diet.

\section{Low-density lipoprotein oxidation}

Nestel et al. (1997) found that the lag time of $\mathrm{Cu}$-induced oxidation of LDL was significantly lower (by $14 \mathrm{~min}$; about $22 \%)$ after consumption of an $\alpha$ LNA-rich $(20 \mathrm{~g} / \mathrm{d})$ low-fat (26\% energy from fat) diet compared with a monounsaturated fat-rich low-fat-diet. In addition, the content of thiobarbituric acid reactive substances in the oxidised LDL was higher if the LDL came from subjects on the $\alpha$ LNArich diet (Nestel et al. 1997). However, Finnegan et al. (2003b) reported no effect of diets containing 4.5 or $9 \mathrm{~g}$ $\alpha \mathrm{LNA} / \mathrm{d}$ on lag time of LDL oxidation, compared with study entry or with an LA-rich diet. Ezaki et al. (1999) found no effect of $4 \cdot 2 \mathrm{~g} \alpha \mathrm{LNA} / \mathrm{d}$ on plasma lipid peroxide or oxidised LDL concentrations in elderly Japanese subjects.

\section{Blood pressure}

Berry \& Hirsch (1986) noted that a $1 \%$ increase in adipose tissue $\alpha$ LNA content was associated with a $5 \mathrm{mmHg}$ decrease in systolic and diastolic blood pressure. Salonen et al. (1988) reported an inverse association between $\alpha$ LNA consumption and blood pressure in a large prospective study. However, $38 \mathrm{~g} \alpha \mathrm{LNA} / \mathrm{d}$ for 2 weeks did not affect systolic or diastolic blood pressure in normotensive or hypertensive subjects (Singer et al. 1986). Likewise, $9.2 \mathrm{~g}$ $\alpha \mathrm{LNA} / \mathrm{d}$ did not affect systolic or diastolic blood pressure in a 6-week intervention study in normotensive hypercholesterolaemic subjects (Kestin et al. 1990). Furthermore, 6.3 g $\alpha \mathrm{LNA} / \mathrm{d}$ for 2 years did not affect systolic or diastolic blood pressure in subjects with multiple cardiovascular risk factors (Bemelmans et al. 2002); some of these subjects were under antihypertensive therapy.

\section{Vascular reactivity}

Nestel et al. (1997) found increased arterial compliance (aortic flow velocity and aortic root driving pressure) after 4 
weeks of $20 \mathrm{~g} \alpha \mathrm{LNA} / \mathrm{d}$ (9\% energy) (and $2.7 \%$ energy as LA) in exchange for oleic acid in obese subjects.

\section{Haemostasis and platelet aggregation}

Increased consumption of $\alpha$ LNA results in an increased content of EPA and DPA in platelets (see Table 4) in parallel with a decreased content of arachidonic acid. This might be expected to affect platelet aggregation, since this is regulated in part by arachidonic acid- and EPA-derived eicosanoids (Needleman et al. 1979; Knapp et al. 1986). Indeed, healthy men consuming a high- $\alpha$ LNA diet $(8.5 \%$ energy from $\alpha \mathrm{LNA}$; approximately $18 \mathrm{~g} / \mathrm{d}$ ) had decreased collagen-induced platelet aggregation compared with those on an LA-rich diet (12\% energy from LA) (Allman et al. 1995). Freese et al. (1994) reported a decrease in ADPinduced platelet aggregation in hyperlipaemic subjects consuming $2.1 \%$ energy as $\alpha$ LNA (and $6.5 \%$ energy as LA) compared with a low- $\alpha$ LNA diet $(0.3 \%$ energy from $\alpha$ LNA and $8 \%$ energy from LA). However, there are reports that substantially increased consumption of $\alpha$ LNA $(3 \cdot 7,5.9$ or $15.4 \mathrm{~g} / \mathrm{d}$ ) does not affect platelet aggregation induced by collagen (Freese \& Mutanen, 1997, Li et al. 1999). Furthermore, there was no effect of 6.8 or $10 \mathrm{~g} \alpha \mathrm{LNA} / \mathrm{d}$ on ADP-induced platelet aggregation (Wensing et al. 1999; Junker et al. 2001).

A number of intervention studies report little effect of $\alpha$ LNA on coagulation and fibrinolytic factors, including factor VII, factor XII, fibrinogen, plasminogen activator inhibitor-1 or tissue plasminogen activator concentration or factor VII, plasminogen activator inhibitor-1 or tissue plasminogen activator activity (Table 7). Intakes of $\alpha$ LNA studied have been in the range of 3.7 to $15.4 \mathrm{~g} / \mathrm{d}$ (see Table 7).

\section{Inflammation}

Increased consumption of $\alpha$ LNA results in an increased content of EPA and DPA in the membranes of inflammatory cells such as neutrophils and monocytes (see Table 4) in parallel with a decreased content of arachidonic acid. This might be expected to affect inflammation, since this is regulated in part by arachidonic acid- and EPA-derived eicosanoids (see Lewis et al. 1990; Tilley et al. 2001; Calder 2003, 2004b, 2005). A recent study reported an inverse association between $\alpha$ LNA intake and plasma concentrations of IL-6 and soluble vascular cell adhesion molecule-1 but not of C-reactive protein (CRP), soluble TNF receptor-2, soluble E-selectin or soluble intercellular adhesion molecule-1 in samples taken from the Nurses' Health Study 1 cohort (Lopez-Garcia et al. 2004). After adjustment for age, BMI, physical activity, smoking status, alcohol consumption and intakes of LA and SFA, there were significant negative associations between $\alpha$ LNA intake and plasma CRP, IL-6, and soluble E-selectin concentrations (Lopez-Garcia et al. 2004). These observations would suggest that increasing $\alpha$ LNA intake would result in decreased inflammation. Table 8 summarises intervention studies that have investigated the effect of $\alpha$ LNA on inflammatory outcomes in human subjects; some studies have examined the circulating concentrations of inflammatory markers such as CRP, soluble adhesion molecules or cytokines (Junker et al. 2001; Thies et al. 2001a; Rallidis et al. 2003, 2004; Bemelmans et al. 2004; Zhao et al. 2004), while other studies have examined inflammatory cell responses ex vivo (Caughey et al. 1996; Healy et al. 2000; Thies et al. 2001a; Kew et al. 2003; Wallace et al. 2003). Caughey et al. (1996) reported that $13.7 \mathrm{~g} \alpha \mathrm{LNA} / \mathrm{d}$ for 4 weeks resulted in a decrease in ex vivo production of prostaglandin $\mathrm{E}_{2}, \mathrm{TNF}-\alpha$ and IL-1 $\beta$ by endotoxin-stimulated mononuclear cells by 33,27 and $30 \%$, respectively. By comparison, fish oil providing $2.7 \mathrm{~g}$ $\mathrm{EPA}+\mathrm{DHA} / \mathrm{d}$ decreased production of these inflammatory mediators by 55, 70 and $78 \%$ respectively (Caughey et al. 1996). Thus on a g/d basis, long-chain $n$-3 PUFA are about eight to fourteen times more potent than $\alpha$ LNA with respect to this outcome in healthy subjects. In contrast to the observations of Caughey et al. (1996), several studies using lower intakes of $\alpha \mathrm{LNA}$ ( 2 to $9.5 \mathrm{~g} / \mathrm{d}$ ) did not find effects on neutrophil chemotaxis, neutrophil respiratory burst, monocyte respiratory burst, TNF- $\alpha$, IL- $1 \beta$ and IL- 6 production by endotoxin-stimulated mononuclear cells, all studied ex vivo, or on soluble adhesion molecule concentrations (for details, see Table 8). Furthermore, a study by Rallidis et al. (2004) reported no effect of $8 \mathrm{~g} \alpha \mathrm{LNA} / \mathrm{d}$ on soluble intercellular adhesion molecule- 1 or soluble E-selectin concentrations and a similar decrease in soluble vascular cell adhesion molecule- 1 concentration in both $\alpha$ LNA and control groups. Likewise, Bemelmans et al. (2004) found no effect of $6 \cdot 3 \mathrm{~g}$ $\alpha \mathrm{LNA} / \mathrm{d}$ on soluble intercellular adhesion molecule- 1 concentration at 1 and 2 years of intervention. Taken together, these data suggest that increasing $\alpha$ LNA intake to $>9 \mathrm{~g} / \mathrm{d}$ is required in order for marked anti-inflammatory effects to be seen. Even then, the effects will be much more modest than those exerted by long-chain $n-3$ PUFA (Caughey et al. 1996). However, both Rallidis et al. (2003) and Bemelmans et al. (2004) did find a significant decrease in CRP concentration, suggesting that this may be a marker that is more sensitive to intakes of $\alpha$ LNA that do not affect soluble adhesion molecule or cytokine concentrations or ex vivo inflammatory cell responses. One study using a very high intake of $\alpha$ LNA (approximately $17.5 \mathrm{~g} / \mathrm{d}$ ) reported significant decreases in both CRP and soluble adhesion molecule concentrations (Zhao et al. 2004). Interestingly, the authors found that the changes in these inflammatory markers were significantly related to changes in serum concentrations of EPA or EPA + DPA, but not of $\alpha$ LNA (Zhao et al. 2004). This suggests that the observed effects are due to the long-chain $n$-3 PUFA rather than to $\alpha$ LNA per se. Thus the probable explanation for the lack of anti-inflammatory effect of $\alpha \mathrm{LNA}$ at modest (Healy et al. 2000; Thies et al. 2001a; Kew et al. 2003; Wallace et al. 2003), and even at rather high (Kew et al. 2003), intakes is that there has been insufficient conversion of $\alpha$ LNA to the more active EPA.

\section{$\alpha$-Linolenic acid and immune function}

A limited number of studies have investigated the effect of $\alpha$ LNA on immune functions in human subjects, apart from those with an inflammatory component. Table 9 summarises the studies that exist in this area. These studies have 


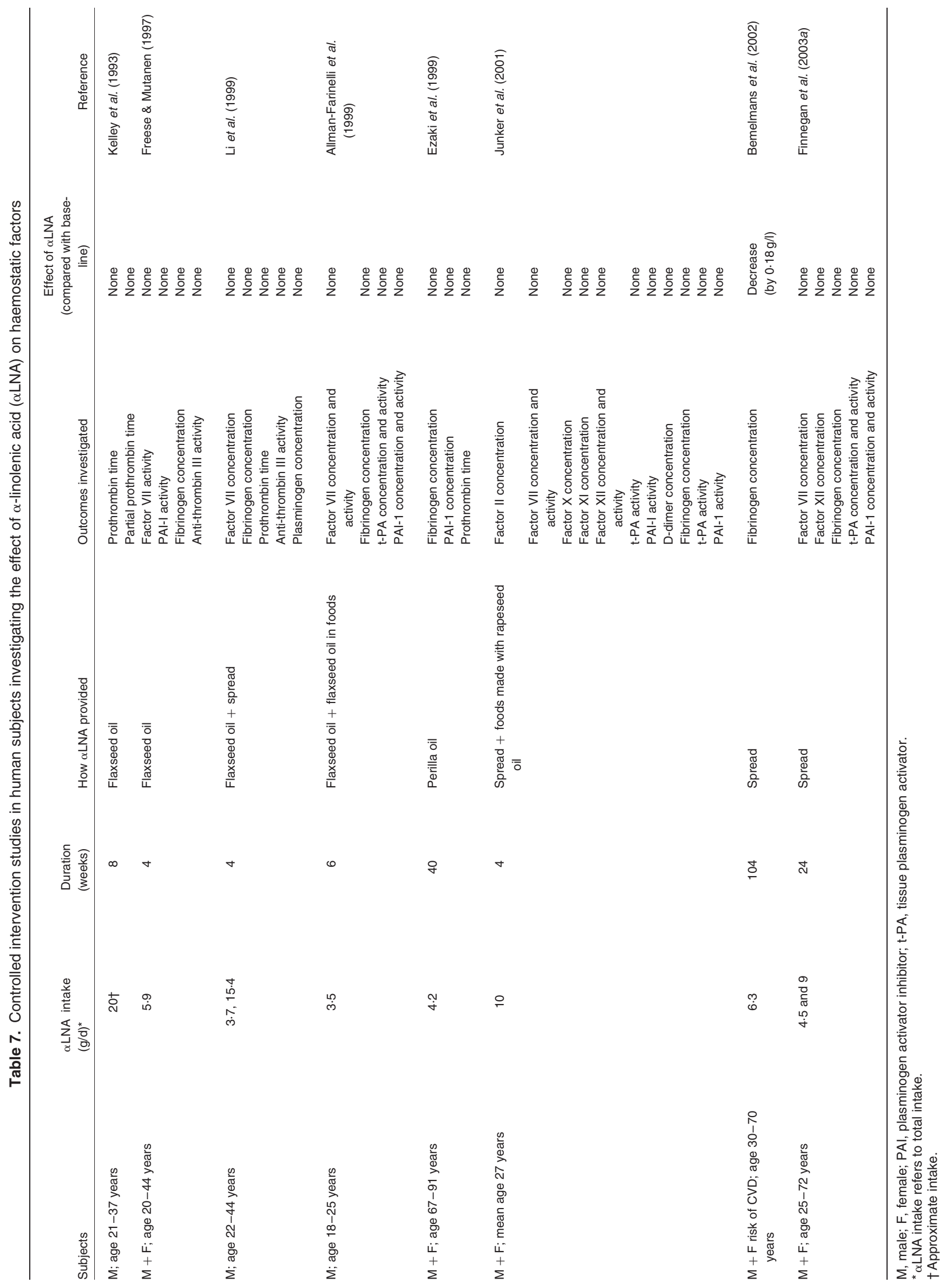




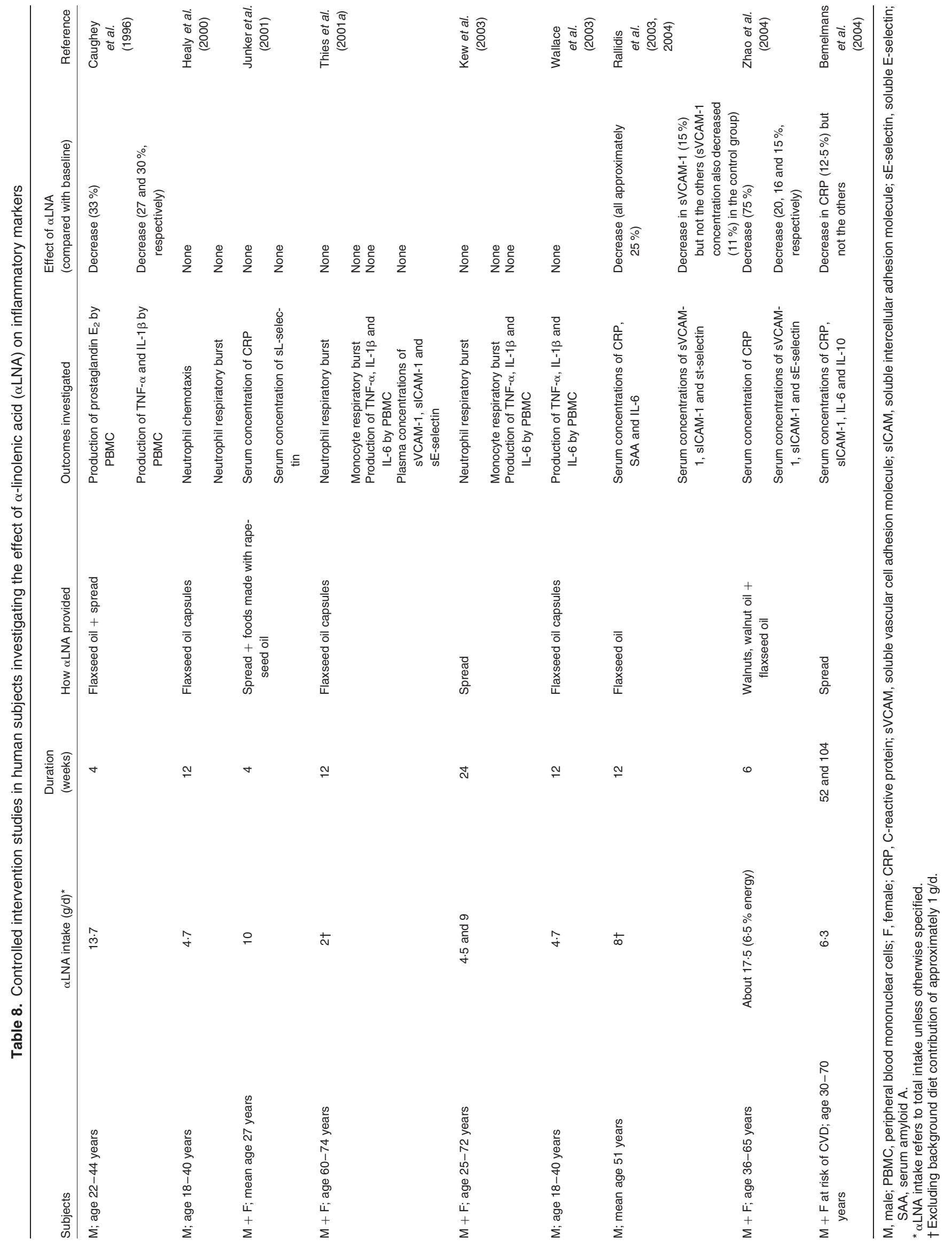




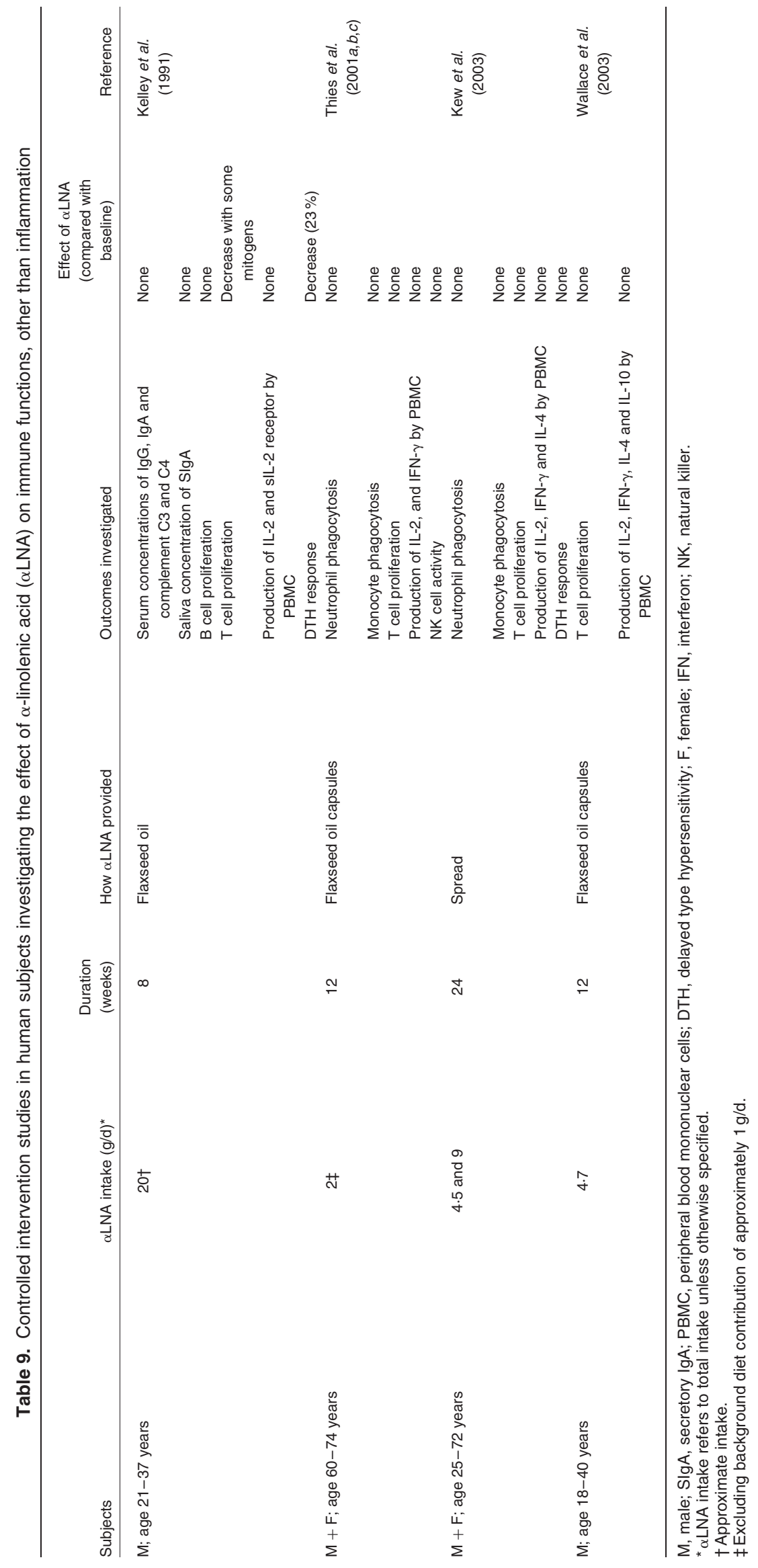


investigated ex vivo immune cell functions such as phagocytosis of bacteria, lymphocyte proliferation and cytokine production in response to mitogenic stimulation and in vivo responses to antigen challenge (delayed type hypersensitivity response). It is evident that increasing $\alpha$ LNA intake to as much as $9 \mathrm{~g} / \mathrm{d}$ has no effect on those human immune functions examined in these studies (Table 9). One study using a very high intake of $\alpha$ LNA (approximately $20 \mathrm{~g} / \mathrm{d}$ ) reported significant decreases in some immune parameters, but not others (Kelley et al. 1991). T cell proliferation was decreased in response to one mitogen but not others and the significance of this is not clear. However, the observed decreased delayed type hypersensitivity response, which is the summation of the in vivo response to intradermal challenge with seven antigens, is in accordance with decreased $\mathrm{T}$ cell function. Thus, very high intakes of $\alpha$ LNA might impair $\mathrm{T}$ cellmediated immune responses.

\section{Conclusions}

Epidemiological studies show that $\alpha$ LNA intake is inversely associated with risk of CVD. This inverse relationship may explain the benefit on mortality seen in an intervention study that involved increased $\alpha$ LNA intake (de Lorgeril et al. 1994). Intervention studies are indicative that substantially increased $\alpha$ LNA intake can beneficially affect a range of cardiovascular risk factors including blood cholesterol (Chan et al. 1991; Cunnane et al. 1995; Arjmandi et al. 1998; Junker et al. 2001; Sodergren et al. 2001; Karvonen et al. 2002; Zhao et al. 2004), LDL-cholesterol (Chan et al. 1991; Cunnane et al. 1995; Arjmandi et al. 1998; Junker et al. 2001; Sodergren et al. 2001; Bemelmans et al. 2002; Karvonen et al. 2002; Zhao et al. 2004) and TAG (Singer et al. 1986; Zhao et al. 2004) concentrations, vascular reactivity (Nestel et al. 1997), platelet aggregation (Allman et al. 1995) and inflammation (Caughey et al. 1996; Zhao et al. 2004). However, the effect on cholesterol concentration is similar to that of LA, while $\alpha$ LNA is less potent than LA at decreasing LDL concentration (Mantzioris et al. 1994; Pang et al. 1998). Furthermore $\alpha$ LNA can decrease HDL concentration (Nestel et al. 1997; Junker et al. 2001; Rallidis et al. 2003) which LA does not do and, in contrast to the effects of long-chain n-3 PUFA, may increase TAG concentration. More modest increases in $\alpha \mathrm{LNA}$ intake do not affect blood lipid concentrations, postprandial lipaemia, blood pressure, platelet aggregation, haemostatic factors, inflammation or immune function. These effects contrast with those of long-chain $n-3$ PUFA and it is apparent from studies where $\alpha$ LNA and long-chain $n$ - 3 PUFA have been compared that $\alpha \mathrm{LNA}$ is substantially less potent (for example, Caughey et al. 1996). The reason why very high intakes of $\alpha$ LNA may induce qualitatively similar effects to those of long-chain n-3 PUFA (for example, decreasing TAG concentration, platelet aggregation and inflammation), while lower intakes do not, may be that the high intakes allow sufficient synthesis of EPA to occur to induce biologically effective changes in EPA concentration. This is borne out by the observations of Zhao et al. (2004) that the $\alpha$ LNA-induced changes in inflammatory markers were significantly related to changes in serum concentrations of
EPA or EPA + DPA, but not of $\alpha$ LNA. Similar to this, Caughey et al. (1996) related the effects of $\alpha$ LNA on inflammatory cytokine production to the increased content of EPA in mononuclear cells. Thus, the probable explanation for the lack of biological effect of more modest intakes of $\alpha \mathrm{LNA}$ is that there has been insufficient conversion of $\alpha \mathrm{LNA}$ to the more active EPA. From this point of view increased intake of $\alpha$ LNA offers little real advantage compared with increased intake of long-chain $n-3$ PUFA, and may even be disadvantageous if $\alpha$ LNA does increase blood TAG concentration. One clear advantage of increased $\alpha$ LNA intake is that it seems unlikely to make LDL more sensitive to oxidation, a process which can be promoted by long-chain $n-3$ PUFA. Once again, the fact that one study using a very high intake of $\alpha$ LNA reported increased susceptibility of LDL to oxidation (Nestel et al. 1997) may reflect the fact that the LDL may have been significantly richer in EPA and DPA as a result of $\alpha$ LNA conversion.

\section{Overall conclusions}

Human conversion of $\alpha$ LNA to its longer-chain derivatives, especially DHA, is limited, although conversion is greater in women than men. The limited extent to which $\alpha \mathrm{LNA}$ is converted to its longer-chain metabolites may explain, at least in part, the relative lack of effectiveness of increased consumption of $\alpha \mathrm{LNA}$ on risk factors for CVD, inflammatory markers, and immune function. Dietary intervention studies with $\alpha$ LNA have been conducted either in men or in mixed groups of men and women, and the effect of increased $\alpha$ LNA intake on health outcomes in young women has not been investigated. Since young women possess greater capacity for conversion to EPA and DHA, it is possible that they may exhibit a greater response in terms of health outcomes to increased dietary intake of $\alpha$ LNA. For example, increased $\alpha$ LNA intake may lead to greater reserves of EPA and DHA in adipose tissue which could be mobilised and supplied to the fetus during pregnancy. Furthermore, increased dietary intake of $\alpha$ LNA by young women may provide a means of ameliorating inflammatory disease symptoms. Thus there is a need for more research investigating the role of $\alpha$ LNA in promoting health in young women.

\section{References}

Adolph EF \& Heggeness FW (1971) Age changes in body water and fat in fetal and infant mammals. Growth 35, 55-63.

Allman MA, Pena MM \& Pang D (1995) Supplementation with flaxseed oil versus sunflowerseed oil in healthy young men consuming a low fat diet: effects on platelet composition and function. European Journal of Clinical Nutrition 49, 169-178.

Allman-Farinelli MA, Hall D, Kingham K, Pang D, Petocz P \& Favaloro EJ (1999) Comparison of the effects of two low fat diets with different alpha-linolenic:linoleic acid ratios on coagulation and fibrinolysis. Atherosclerosis 142, 159-168.

Anderson RE (1970) Lipids of ocular tissues. IV. A comparison of the phospholipids from the retina of six mammalian species. Experimental Eye Research 10, 339-344.

Arjmandi BH, Khan DA, Juma S, Drum ML, Venkatesh S, Sohn E, Wei L \& Derman R (1998) Whole flaxseed consumption lowers 
serum LDL-cholesterol and lipoprotein(a) concentrations in postmenopausal women. Nutrition Research 18, 1203-1214.

Ascherio A, Rimm EB, Giovannucci EL, Spiegelman D, Stampfer M \& Willett WC (1996) Dietary fat and risk of coronary heart disease in men: cohort follow up study in the United States. BMJ 313, 84-90.

Astorg P, Arnault N, Czernichow S, Noisette N, Galan P \& Hercberg S (2004) Dietary intakes and food sources of n-6 and n-3 PUFA in French adult men and women. Lipids 39, 527-535.

Bang HO, Dyerberg J \& Hjoorne N (1976) The composition of food consumed by Greenland Eskimos. Acta Medica Scandinavia 200, 69-73.

Baylin A, Kabagambe EK, Ascherio A, Spiegelman D \& Campos H (2003) Adipose tissue alpha-linolenic acid and nonfatal acute myocardial infarction in Costa Rica. Circulation 107, $1586-1591$

Bemelmans WJ, Broer J, Feskens EJ, Smit AJ, Muskiet FA, Lefrandt JD, Bom VJ, May JF \& Meyboom-de Jong B (2002) Effect of an increased intake of alpha-linolenic acid and group nutritional education on cardiovascular risk factors: the Mediterranean Alpha-linolenic Enriched Groningen Dietary Intervention (MARGARIN) study. American Journal of Clinical Nutrition 75, 221-227.

Bemelmans WJ, Lefrandt JD, Feskens EJ, van Haelst PL, Broer J, Meyboom-de Jong B, May JF, Tervaert JW \& Smit AJ (2004) Increased alpha-linolenic acid intake lowers C-reactive protein, but has no effect on markers of atherosclerosis. European Journal of Clinical Nutrition 58, 1083-1089.

Berry EM \& Hirsch J (1986) Does dietary linolenic acid influence blood pressure? American Journal of Clinical Nutrition 44, 336-340.

Bieri JG \& Prival EL (1965) Lipid composition of testes from various species. Comparative Biochemistry and Physiology 15, 275-282.

Bjerregaard P \& Dyerberg J (1988) Fish oil and ischaemic heart disease in Greenland. Lancet ii, 514.

Bretillon L, Chardigny JM, Sebedio JL, Noel JP, Scrimgeour CM, Fernie CE, Loreau O, Gachon P \& Beaufrere B (2001) Isomerization increases the postprandial oxidation of linoleic acid but not $\alpha$-linolenic acid in men. Journal of Lipid Research 42, 995-997.

British Nutrition Foundation (1992) Unsaturated Fatty Acids: Nutritional and Physiological Significance. London: Chapman \& Hall.

Broadhurst CL, Wang Y, Crawford MA, Cunnane SC, Parkington JE \& Schmidt WF (2002) Brain-specific lipids from marine, lacustrine, or terrestrial food resources: potential impact on early African Homo sapiens. Comparative Biochemistry and Physiology 131B, 653-673.

Brouwer IA, Katan MB \& Zock PL (2004) Dietary alpha-linolenic acid is associated with reduced risk of fatal coronary heart disease, but increased prostate cancer risk: a meta-analysis. Journal of Nutrition 134, 919-922.

Bucher HC, Hengstler P, Schindler C \& Meier G (2002) n-3 Polyunsaturated fatty acids in coronary heart disease: a metaanalysis of randomized controlled trials. American Journal of Medicine 112, 298-304.

Burdge GC, Derrick PR, Russell JJ, Tricon S, Kew S, Banerjee T, Grimble RF, Williams CM, Yaqoob P \& Calder PC (2005) Incorporation of cis- 9 , trans-11 or trans-10, cis-12 conjugated linoleic acid into human erythrocytes in vivo. Nutrition Research 25, 13-19.

Burdge GC, Finnegan YE, Minihane AM, Williams CM \& Wootton SA (2003) Effect of altered dietary $n-3$ fatty aid intake upon plasma lipid fatty acid composition, conversion of $\left[{ }^{13} \mathrm{C}\right] \alpha$-linolenic acid to longer-chain fatty acids and partitioning towards $\beta$-oxidation in older men. British Journal of Nutrition 90, 311-321.

Burdge GC, Hunt AN \& Postle AD (1994) Mechanisms of hepatic phosphatidylcholine synthesis in adult rat: effects of pregnancy. Biochemical Journal 303, 941-947.

Burdge GC, Jones AE \& Wootton SA (2002) Eicosapentaenoic and docosapentaenoic acids are the principal products of $\alpha$-linolenic acid metabolism in young men. British Journal of Nutrition $\mathbf{8 8}$, 355-363.

Burdge GC \& Wootton SA (2002) Conversion of $\alpha$-linolenic acid to eicosapentaenoic, docosapentaenoic and docosahexaenoic acids in young women. British Journal of Nutrition 88, 411-420.

Burdge GC \& Wootton SA (2003) Conversion of $\alpha$-linolenic acid to palmitic, palmitoleic, stearic and oleic acids in men and women. Prostaglandins, Leukotrienes and Essential Fatty Acids 69, 283-290.

Calder PC (2001) Polyunsaturated fatty acids, inflammation and immunity. Lipids 36, 1007-1024.

Calder PC (2002) Dietary modification of inflammation with lipids. Proceedings of the Nutrition Society 61, 345-358.

Calder PC (2003) n-3 Polyunsaturated fatty acids and inflammation: from molecular biology to the clinic. Lipids 38, 342-352.

Calder PC (2004a) n-3 Fatty acids and cardiovascular disease: evidence explained and mechanisms explored. Clinical Science 107, 1-11.

Calder PC (2004b) n-3 Fatty acids, inflammation and immunity relevance to postsurgical and critically ill patients. Lipids 39, $1147-1161$.

Calder PC (2005) Polyunsaturated fatty acids and inflammation. Biochemical Society Transactions 33, 423-427.

Calder PC, Yaqoob P, Thies F, Wallace FA \& Miles EA (2002) Fatty acids and lymphocyte functions. British Journal of Nutrition 87, S31-S48.

Carnielli VP, Wattimena DJ, Luijendijk IH, Boerlage A, Degenhart HJ \& Sauer PJ (1996) The very-low-birth-weight premature infant is capable of synthesizing arachidonic and docosahexaenoic acid from linolenic and linolenic acid. Pediatric Research 40, 169-174.

Caughey GE, Mantzioris E, Gibson RA, Cleland LG \& James MJ (1996) The effect on human tumor necrosis factor alpha and interleukin 1 beta production of diets enriched in $n-3$ fatty acids from vegetable oil or fish oil. American Journal of Clinical Nutrition 63, 116-122.

Chan JK, Bruce VM \& McDonald BE (1991) Dietary alphalinolenic acid is as effective as oleic acid and linoleic acid in lowering blood cholesterol in normolipidemic men. American Journal of Clinical Nutrition 53, 1230-1234.

Chan JK, McDonald BE, Gerrard JM, Bruce VM, Weaver BJ \& Holub BJ (1993) Effect of dietary alpha-linolenic acid and its ratio to linoleic acid on platelet and plasma fatty acids and thrombogenesis. Lipids 28, 811-817.

Chang MC, Bell JM, Purdon AD, Chikhale EG \& Grange E (1999) Dynamics of docosahexaenoic acid metabolism in the central nervous system: lack of effect of chronic lithium treatment. Neurochemistry Research 24, 399-406.

Chapkin RS, Ziboh VA, Marcelo CL \& Voorhees JJ (1986) Metabolism of essential fatty acids by human epidermal enzyme preparations: evidence of chain elongation. Journal of Lipid Research 27, 945-954.

Chin JPF, Gust A, Nestel PJ \& Dart AM (1993) Fish oils dosedependently inhibit vasoconstriction of forearm resistance vessels in humans. Hypertension 21, 22-28.

Cho HP, Nakamura M \& Clarke SD (1999) Cloning, expression, and fatty acid regulation of the human delta-5 desaturase. Journal of Biological Chemistry 274, 37335-37339. 
Christensen JH, Gustenhoff P, Korup E, Aaroe J, Toft E, Moller J, Rasmussen K, Dyerberg J \& Schmidt EB (1996) Effect of fish oil on heart rate variability in survivors of myocardial infarction: a double blind randomised controlled trial. BMJ 312, 677-678.

Christensen JH, Skou HA, Fog L, Hansen V, Vesterlund T, Dyerberg J, Toft E \& Schmidt EB (2001) Marine n-3 fatty acids, wine intake, and heart rate variability in patients referred for coronary angiography. Circulation 103, 651-657.

Clandinin MT, Chappell JE, Heim T, Swyer PR \& Chance GW (1981) Fatty acid utilization in perinatal de novo synthesis of tissues. Early Human Development 5, 355-366.

Clouet P, Niot I \& Bezard J (1989) Pathway of alpha-linolenic acid through the mitochondrial outer membrane in the rat liver and influence on the rate of oxidation. Comparison with linoleic and oleic acids. Biochemical Journal 263, 867-873.

Connor WE \& Neuringer M (1988) The effects of n-3 fatty acid deficiency and repletion upon the fatty acid composition and function of the brain and retina. Progress in Clinical and Biological Research 282, 275-294.

Correia HR, Balseiro SC, Correia ER, Mota PG \& de Areia ML (2004) Why are human newborns so fat? Relationship between fatness and brain size at birth. American Journal of Human Biology 16, 24-30.

Crawford MA, Casperd NM \& Sinclair AJ (1976) The long chain metabolites of linoleic and linolenic acids in liver and brain in herbivores and carnivores. Comparative Biochemistry and Physiology 54B, 395-401.

Cunnane SC, Hamadeh MJ, Liede AC, Thompson LU, Wolever TM \& Jenkins DJ (1995) Nutritional attributes of traditional flaxseed in healthy young adults. American Journal of Clinical Nutrition 61, 62-68.

Cunnane SC, Ryan MA, Nadeau CR, Bazinet RP, Musa-Veloso K \& McCloy U (2003) Why is carbon from some polyunsaturates extensively recycled in lipid synthesis? Lipids 38, 477-484.

Cunnane SC, Williams SC, Bell JD, Brookes S, Craig K, Iles RA \& Crawford MA (1994) Utilization of uniformly labeled ${ }^{13} \mathrm{C}$-polyunsaturated fatty acids in the synthesis of long-chain fatty acids and cholesterol accumulating in the neonatal rat brain. Journal of Neurochemistry 62, 2429-2436.

D' andrea S, Guillou H, Jan S, Catheline D, Thibault JN, Bouriel M, Rioux V \& Legrand P (2002) The same rat $\Delta 6$-desaturase not only acts on 18- but also on 24-carbon fatty acids in very-longchain polyunsaturated fatty acid biosynthesis. Biochemical Journal 364, 49-55.

de Antueno RJ, Knickle LC, Smith H, Elliot ML, Allen SJ, Nwaka S $\&$ Winther MD (2001) Activity of human $\Delta 5$ and $\Delta 6$ desaturases on multiple n-3 and n-6 polyunsaturated fatty acids. FEBS Letters $\mathbf{5 0 9}, 77-80$.

de Gomez Dumm IN \& Brenner RR (1975) Oxidative desaturation of alpha-linoleic, linoleic, and stearic acids by human liver microsomes. Lipids 10, 315-317.

de Lorgeril M, Renaud S, Mamelle N, Salen P, Martin JL, Monjaud I, Guidollet J, Touboul P \& Delaye J (1994) Mediterranean alpha-linolenic acid-rich diet in secondary prevention of coronary heart disease. Lancet 343, 1454-1459.

Del Prado M, Villalpando S, Elizondo A, Rodriguez M, Demmelmair H \& Koletzko B (2001) Contribution of dietary and newly formed arachidonic acid to human milk lipids in women eating a low-fat diet. American Journal of Clinical Nutrition 74, 242-247.

DeLany JP, Windhauser MM, Champagne CM \& Bray GA (2000) Differential oxidation of individual dietary fatty acids in humans. American Journal of Clinical Nutrition 72, 905-911.

Djousse L, Arnett DK, Carr JJ, Eckfeldt JH, Hopkins PN, Province MA \& Ellison RC (2005) Investigators of the NHLBI FHS Dietary linolenic acid is inversely associated with calcified atherosclerotic plaque in the coronary arteries: the National
Heart. Lung, and Blood Institute Family Heart Study. Circulation 111, 2921-2926.

Djousse L, Folsom AR, Province MA, Hunt SC \& Ellison RC (2003) Dietary linolenic acid and carotid atherosclerosis: the National Heart, Lung, and Blood Institute Family Heart Study. American Journal of Clinical Nutrition 77, 819-825.

Djousse L, Pankow JS, Eckfeldt JH, Folsom AR, Hopkins PN, Province MA, Hong Y \& Ellison RC (2001) Relation between dietary linolenic acid and coronary artery disease in the National Heart, Lung, and Blood Institute Family Heart Study. American Journal of Clinical Nutrition 74, 612-619.

Dolecek TA (1992) Epidemiological evidence of relationships between dietary polyunsaturated fatty acids and mortality in the multiple risk factor intervention trial. Proceedings of the Society for Experimental Biology and Medicine 200, 177-182.

Dyerberg J, Bang HO, Stoffersen E, Moncada S \& Vane JR (1978) Eicosapentaenoic acid and prevention of thrombosis and atherosclerosis? Lancet ii, 117-119.

Emken EA (2001) Stable isotope approaches, applications and issues related to polyunsaturated fatty acid metabolism studies. Lipids 36, 965-973.

Emken EA, Adlof RO, Duval SM \& Nelson GJ (1999) Effect of dietary docosahexaenoic acid on desaturation and uptake in vivo of isotope-labeled oleic, linoleic and linolenic acids by male subjects. Lipids 34, 785-798.

Emken EA, Adlof RO \& Gulley RM (1994) Dietary linoleic acid influences desaturation and acylation of deuterium-labeled linoleic and linolenic acids in young adult males. Biochimica et Biophysica Acta 1213, 277-288.

Evans K, Burdge GC, Wootton SA, Clark ML \& Frayn KN (2002) Regulation of dietary fatty acid entrapment in subcutaneous adipose tissue and skeletal muscle. Diabetes 51, 2684-2690.

Ezaki O, Takahashi M, Shigematsu T, Shimamura K, Kimura J, Ezaki H \& Gotoh T (1999) Long-term effects of dietary alphalinolenic acid from perilla oil on serum fatty acids composition and on the risk factors of coronary heart disease in Japanese elderly subjects. Journal of Nutrition Science Vitaminology (Tokyo) 45, 759-772.

Fernstrom JD (1999) Effects of dietary polyunsaturated fatty acids on neuronal function. Lipids 34, 161-169.

Finnegan YE, Howarth D, Minihane AM, Kew S, Miller GJ, Calder PC \& Williams CM (2003a) Plant and marine derived (n-3) polyunsaturated fatty acids do not affect blood coagulation and fibrinolytic factors in moderately hyperlipidemic humans. Journal of Nutrition 133, 2210-2213.

Finnegan YE, Minihane AM, Leigh-Firbank EC, Kew S, Meijer GW, Muggli R, Calder PC \& Williams CM (2003b) Plant- and marine-derived n-3 polyunsaturated fatty acids have differential effects on fasting and postprandial blood lipid concentrations and on the susceptibility of LDL to oxidative modification in moderately hyperlipidemic subjects. American Journal of Clinical Nutrition 77, 783-795.

Francois CA, Connor SL, Bolewicz LC \& Connor WE (2003) Supplementing lactating women with flaxseed oil does not increase docosahexaenoic acid in their milk. American Journal of Clinical Nutrition 77, 226-233.

Freese R \& Mutanen M (1997) Alpha-linolenic acid and marine long-chain n-3 fatty acids differ only slightly in their effects on hemostatic factors in healthy subjects. American Journal of Clinical Nutrition 66, 591-598.

Freese R, Mutanen M, Valsta LM \& Salminen I (1994) Comparison of the effects of two diets rich in monounsaturated fatty acids differing in their linoleic/alpha-linolenic acid ratio on platelet aggregation. Thrombosis and Haemostasis 71, 73-77.

Ge L, Gordon JS, Hsuan C, Stenn K \& Prouty SM (2003) Identification of the delta- 6 desaturase of human sebaceous 
glands: expression and enzyme activity. Journal of Investigative Dermatology 120, 707-714.

Geleijnse JM, Giltay EJ, Grobbee DE, Donders AR \& Kok FJ (2002) Blood pressure response to fish oil supplementation: metaregression analysis of randomized trials. Journal of Hypertension 20, 1493-1499.

Gibbons A (2002a) American Association of Physical Anthropologists meeting. Humans' head start: new views of brain evolution. Science 296, 835-837.

Gibbons A (2002b) Becoming human. In search of the first hominids. Science 295, 1214-1219.

Giltay EJ, Duschek EJ, Katan MB, Zock PL, Neele SJ \& Netelenbos JC (2004a) Raloxifene and hormone replacement therapy increase arachidonic acid and docosahexaenoic acid levels in postmenopausal women. Journal of Endocrinology 182, 399-408.

Giltay EJ, Gooren LJ, Toorians AW, Katan MB \& Zock PL (2004b) Docosahexaenoic acid concentrations are higher in women than in men because of estrogenic effects. American Journal of Clinical Nutrition 80, 1167-1174.

Goode GK, Garcia S \& Heagerty AM (1997) Dietary supplementation with marine fish oil improves in vitro small artery endothelial function in hypercholesterolemic patients: a double-blind placebo-controlled study. Circulation 96, 2802-2807.

Goodnight SH, Harris WS \& Connor WE (1981) The effects of dietary omega 3 fatty acids on platelet composition and function in man: a prospective, controlled study. Blood 58, 880-885.

Goyens PL, Spilker ME, Zock PL, Katan MB \& Mensink RP (2005) Development of a compartmental model to quantify alpha-linolenic acid conversion after longer-term intake of multiple tracer boluses. Journal of Lipid Research 46, $1474-1483$

Gregersen MI \& Rawson RA (1959) Blood volume. Physiological Reviews 39, 307-342.

Hacia JG (2001) Genome of the apes. Trends in Genetics 17, 637-645.

Harmon SD, Kaduce TL, Manuel TD \& Spector AA (2003) Effect of $\Delta 6$-desaturase inhibitor SC-26196 on PUFA metabolism in human cells. Lipids 38, 469-476.

Harris WS (1996) n-3 Fatty acids and lipoproteins: comparison of results from human and animal studies. Lipids 31, 243-252.

He K, Rimm EB, Merchant A, Rosner BA, Stampfer MJ, Willett WC \& Ascherio A (2004) Fish consumption and risk of stroke in men. JAMA 288, 3130-3136.

Healy DA, Wallace FA, Miles EA, Calder PC \& Newsholm P (2000) Effect of low-to-moderate amounts of dietary fish oil on neutrophil lipid composition and function. Lipids 35, 763-768.

Heath RB, Karpe F, Milne RW, Burdge GC, Wootton SA \& Frayn KN (2003) Selective partitioning of dietary fatty acids into the VLDL TG pool in the early postprandial period. Journal of Lipid Research 44, 2065-2072.

Hu FB, Stampfer MJ, Manson JE, Rimm EB, Wolk A, Colditz GA, Hennekens CH \& Willett WC (1999) Dietary intake of alphalinolenic acid and risk of fatal ischemic heart disease among women. American Journal of Clinical Nutrition 69, 890-897.

Hulshof KFAM, van Erp-Baart MA, Anttolainen M, Becker W, Church SM, Couet C, Hermann-Kunz E, Kesteloot H, Leth T, Martins I, Moreiras O, Moschandreas J, et al. (1999) Intake of fatty acids in Western Europe with emphasis on trans fatty acids: the TRANSFAIR Study. European Journal of Clinical Nutrition 53, 143-157.

Hussein N, Ah-Sing E, Wilkinson P, Leach C, Griffin BA \& Millward DJ (2005) Relative rates of long chain conversion of ${ }^{13} \mathrm{C}$ linoleic and $\alpha$-linolenic acid in response to marked changes in their dietary intake in male adults. Journal of Lipid Research 46, 269-280.
Infante JP \& Huszagh VA (1998) Analysis of the putative role of 24-carbon polyunsaturated fatty acids in the biosynthesis of docosapentaenoic (22:5n-6) and docosahexaenoic (22:6n-3) acids. FEBS Letters 43, 1-6.

Innis SM \& Elias SJ (2003) Intakes of essential n-6 and n-3 polyunsaturated fatty acids among pregnant Canadian women. American Journal of Clinical Nutrition 77, 473-478.

Irving CS, Wong WW, Shulman RJ, Smith EO \& Klein PD (1983) $\left[{ }^{13} \mathrm{C}\right]$ Bicarbonate kinetics in humans: intra- vs interindividual variations. American Journal of Physiology 245, R190-R202.

James MJ, Ursin VM \& Cleland LG (2003) Metabolism of stearidonic acid in human subjects: comparison with the metabolism of other n-3 fatty acids. American Journal of Clinical Nutrition 77, 1140-1145.

Jeffrey BG, Weisinger HS, Neuringer M \& Mitchell DC (2001) The role of docosahexaenoic acid in retinal function. Lipids 36, $859-871$.

Junker R, Kratz M, Neufeld M, Erren M, Nofer JR, Schulte H, Nowak-Gottl U, Assmann G \& Wahrburg U (2001) Effects of diets containing olive oil, sunflower oil, or rapeseed oil on the hemostatic system. Thrombosis and Haemostasis 85, 280-286.

Kaminskas A, Zieden B, Elving B, Kristenson M, Abaravicius A, Bergdahl B, Olsson AG \& Kucinskiene Z (1999) Adipose tissue fatty acids in men from two populations with different cardiovascular risk: the LiVicordia study. Scandinavian Journal of Clinical Laboratory Investigation 59, 227-232.

Karvonen HM, Aro A, Tapola NS, Salminen I, Uusitupa MIJ \& Sarkkinen ES (2002) Effect of alpha-linolenic acid-rich Camelina sativa oil on serum fatty acid composition and serum lipids in hypercholesterolemic subjects. Metabolism Clinical and Experimental 51, 1253-1260.

Kelley DS, Branch LB, Love JE, Taylor PC, Rivera YM \& Iacono JM (1991) Dietary alpha-linolenic acid and immunocompetence in humans. American Journal of Clinical Nutrition 53, 40-46.

Kelley DS, Nelson GJ, Love JE, Branch LB, Taylor PC, Schmidt PC, Mackey BE \& Iacono JM (1993) Dietary alpha-linolenic acid alters tissue fatty acid composition, but not blood lipids, lipoproteins or coagulation status in humans. Lipids 28, $533-537$

Kestin M, Clifton P, Belling GB \& Nestel PJ (1990) n-3 Fatty acids of marine origin lower systolic blood pressure and triglycerides but raise LDL cholesterol compared with n-3 and n-6 fatty acids from plants. American Journal of Clinical Nutrition 51, $1028-1034$

Kew S, Banerjee T, Minihane AM, Finnegan YE, Muggli R, Albers R, Williams CM \& Calder PC (2003) Lack of effect of foods enriched with plant- or marine-derived n-3 fatty acids on human immune function. American Journal of Clinical Nutrition 77, $1287-1295$.

Knapp HR, Reilly IA, Alessandrini P \& FitzGerald GA (1986) In vivo indexes of platelet and vascular function during fish-oil administration in patients with atherosclerosis. New England Journal of Medicine 314, 937-942.

Kris-Etherton PM, Harris WS \& Appel LJ (2002) Fish consumption, fish oil, omega-3 fatty acids, and cardiovascular disease. Circulation 106, 2747-2757.

Kris-Etherton PM, Taylor DS, Yu-Poth S, Huth P, Moriarty K, Fishell V, Hargrove RL, Zhao G \& Etherton TD (2000) Polyunsaturated fatty acids in the food chain in the United States. American Journal of Clinical Nutrition 71, Suppl., 179S-188S.

Kromann N \& Green A (1980) Epidemiological studies in the Upernavik district, Greenland. Incidence of some chronic diseases 1950-1974. Acta Medica Scandanavia 208, 401-406.

Kuzawa CW (1998) Adipose tissue in human infancy and childhood: an evolutionary perspective. American Journal of Physical Anthropology 27, Suppl., 177-209. 
Kwon JS, Snook JT, Wardlaw GM \& Hwang DH (1991) Effects of diets high in saturated fatty acids, canola oil, or safflower oil on platelet function, thromboxane B2 formation, and fatty acid composition of platelet phospholipids. American Journal of Clinical Nutrition 154, 351-358.

Lands WE (2003) Diets could prevent many diseases. Lipids 38, $317-321$.

Larque E, Garcia-Ruiz PA, Perez-Llamas F, Zamora S \& Gil A (2003) Dietary trans fatty acids alter the compositions of microsomes and mitochondria and the activities of microsome $\Delta 6$-fatty acid desaturase and glucose-6-phosphatase in livers of pregnant rats. Journal of Nutrition 133, 2526-2531.

Lauritzen L, Hansen HS, Jorgensen MH \& Michaelsen KF (2001) The essentiality of long chain n-3 fatty acids in relation to development and function of the brain and retina. Progress in Lipid Research 40, 1-94.

Layne KS, Goh YK, Jumpsen JA, Ryan EA, Chow P \& Clandinin MT (1996) Normal subjects consuming physiological levels of 18:3(n-3) and 20:5(n-3) from flaxseed or fish oils have characteristic differences in plasma lipid and lipoprotein fatty acid levels. Journal of Nutrition 126, 2130-2140.

Lewis DS, Bertrand HA, Masoro EJ, McGill HC, Carey KD \& McMahan CA (1983) Preweaning nutrition and fat development in baboons. Journal of Nutrition 113, 2253-2259.

Lewis RA, Austen KF \& Soberman RJ (1990) Leukotrienes and other products of the 5-lipoxygenase pathway: biochemistry and relation to pathobiology in human diseases. New England Journal of Medicine 323, 645-655.

Li D, Sinclair A, Wilson A, Nakkote S, Kelly F, Abedin L, Mann N \& Turner A (1999) Effect of dietary alpha-linolenic acid on thrombotic risk factors in vegetarian men. American Journal of Clinical Nutrition 69, 872-882.

Li Z, Kaplan ML \& Hachey DL (2000) Hepatic microsomal and peroxisomal docosahexaenoate biosynthesis during piglet development. Lipids 35, 1325-1333.

Lichtenstein AH, Ausman LM, Carrasco W, Jenner JL, Gualtieri LJ, Goldin BR, Ordovas JM \& Schaefer EJ (1993) Effects of canola, corn, and olive oils on fasting and postprandial plasma lipoproteins in humans as part of a National Cholesterol Education Program Step 2 diet. Arteriosclerosis and Thrombosis 13, 1533-1542.

Lopez-Garcia E, Schulze MB, Fung TT, Meigs JB, Rifai N, Manson JE \& Hu FB (2004) Major dietary patterns are related to plasma concentrations of markers of inflammation and endothelial dysfunction. American Journal of Clinical Nutrition 80, 1029-1035.

Macaulay V, Hill C, Achilli A, Rengo C, Clarke D, Meehan W, Blackburn J, Semino O, Scozzari R, Cruciani F, Taha A, Shaari NK, et al. (2005) Single, rapid coastal settlement of Asia revealed by analysis of complete mitochondrial genomes. Science 308, 1034-1036.

McCloy U, Ryan MA, Pencharz PB, Ross RJ \& Cunnane SCA (2004) Comparison of the metabolism of eighteen-carbon 13Cunsaturated fatty acids in healthy women. Journal of Lipid Research 45, 474-485.

McVeigh GE, Brennan GM, Cohn JN, Finkelstein SM, Hayes RJ \& Johnston GD (1994) Fish oil improves arterial compliance in non-insulin-dependent diabetes mellitus. Arteriosclerosis and Thrombosis 14, 1425-1429.

Mantzioris E, James MJ, Gibson RA \& Cleland LG (1994) Dietary substitution with an alpha-linolenic acid-rich vegetable oil increases eicosapentaenoic acid concentrations in tissues. American Journal of Clinical Nutrition 59, 1304-1309.

Martinez M (2000) The fundamentals and practice of docosahexaenoic acid therapy in peroxisomal disorders. Current Opinion in Clinical Nutrition and Metabolic Care 3, 101-108.
Marzo I, Alava MA, Pineiro A \& Naval J (1996) Biosynthesis of docosahexaenoic acid in human cells: evidence that two different delta 6-desaturase activities may exist. Biochimica et Biophysica Acta 1301, 263-272.

Marzo I, Martinez-Lorenzo MJ, Anel A, Desportes P, Alava MA, Naval J \& Pineiro A (1995) Biosynthesis of unsaturated fatty acids in the main cell lineages of human leukemia and lymphoma. Biochimica et Biophysica Acta 1257, 140-148.

Ministry of Agriculture, Fisheries and Food (1997) Dietary Intake of Iodine and Fatty Acids. Food Information Surveillance Sheet no. 127. London: Ministry of Agriculture, Fisheries and Food.

Mitchell DC, Niu SL \& Litman BJ (2003) Enhancement of G protein-coupled signalling by DHA phospholipids. Lipids 38, 437-443.

Muskiet FA, Fokkema MR, Schaafsma A, Boersma ER \& Crawford MA (2004) Is docosahexaenoic acid (DHA) essential? Lessons from DHA status regulation, our ancient diet, epidemiology and randomized controlled trials. Journal of Nutrition 134, 183-186.

Mutanen M, Freese R, Valsta LM, Ahola I \& Ahlstrom A (1992) Rapeseed oil and sunflower oil diets enhance platelet in vitro aggregation and thromboxane production in healthy men when compared with milk fat or habitual diets. Thrombosis and Haemostasis 67, 352-356.

Needleman P, Wyche A \& Raz A (1979) Platelet and blood vessel arachidonate metabolism and interactions. Journal of Clinical Investigation 63, 345-349.

Nestel PJ, Pomeroy SE, Sasahara T, Yamashita T, Liang YL, Dart AM, Jennings GL, Abbey M \& Cameron JD (1997) Arterial compliance in obese subjects is improved with dietary plant n-3 fatty acid from flaxseed oil despite increased LDL oxidizability. Arteriosclerosis, Thrombosis and Vascular Biology 17, $1163-1170$.

Neuringer M, Connor WE, Lin DS, Barstad L \& Luck S (1986) Biochemical and functional effects of prenatal and postnatal omega 3 fatty acid deficiency on retina and brain in rhesus monkeys. Proceedings of the National Academy of Sciences USA 83, 4021-4025.

Newman WP, Middaugh JP, Propst MT \& Rogers DR (1993) Atherosclerosis in Alaska natives and non-natives. Lancet 341, $1056-1057$.

O'Brien JS \& Sampson EL (1965) Fatty acid and fatty aldehyde composition of the major brain lipids in normal human gray matter, white matter, and myelin. Journal of Lipid Research $\mathbf{6}$, $545-551$.

Ollis TE, Meyer BJ \& Howe PR (1999) Australian food sources and intakes of omega- 6 and omega- 3 polyunsaturated fatty acids. Annals of Nutrition and Metabolism 43, 346-355.

Oomen CM, Ocke MC, Feskens EJ, Kok FJ \& Kromhout D (2001) Alpha-linolenic acid intake is not beneficially associated with 10 -y risk of coronary artery disease incidence: the Zutphen Elderly Study. American Journal of Clinical Nutrition 74, 457-463.

Ottosson UB, Lagrelius A, Rosing U \& von Schoultz B (1984) Relative fatty acids composition of lecithin during postmenopausal replacement therapy - a comparison between ethinyl estradiol and estradiol valerate. Gynaecologic and Obstetric Investigation 18, 296-302.

Pang D, Allman-Farinelli MA, Wong T, Barnes R \& Kingham KM (1998) Replacement of linoleic acid with alpha-linolenic acid does not alter blood lipids in normolipidaemic men. British Journal of Nutrition 80, 163-167.

Pawlosky R, Hibbeln J, Lin Y \& Salem N (2003a) n-3 Fatty acid metabolism in women. British Journal of Nutrition 90, 993-994.

Pawlosky RJ, Hibbeln JR, Lin Y, Goodson S, Riggs P, Sebring N, Brown GL \& Salem N (2003b) Effects of beef- and fish-based 
diets on the kinetics of $n-3$ fatty acid metabolism in human subjects. American Journal of Clinical Nutrition 77, 565-572.

Pawlosky RJ, Hibbeln JR, Novotny JA \& Salem N (2001) Physiological compartmental analysis of $\alpha$-linolenic acid metabolism in adult humans. Journal of Lipid Research $\mathbf{4 2}$, $1257-1265$

Pietinen P, Ascherio A, Korhonen P, Hartman AM, Willett WC, Albanes D \& Virtamo J (1997) Intake of fatty acids and risk of coronary heart disease in a cohort of Finnish men. The AlphaTocopherol, Beta-Carotene Cancer Prevention Study. American Journal of Epidemiology 145, 876-887.

Pischon T, Hankinson SE, Hotamisligil GS, Rifai N, Willett WC \& Rimm EB (2003) Habitual dietary intake of n-3 and n-6 fatty acids in relation to inflammatory markers among US men and women. Circulation 108, 155-160.

Poisson J-P, Dupuy R-P, Sarda P, Descomps B, Narce M, Rieu D \& Crastes de Paulet A (1993) Evidence that liver microsomes of human neonates desaturate essential fatty acids. Biochimica et Biophysica Acta 1167, 109-113.

Poissonnet CM, Burdi AR \& Garn SM (1984) The chronology of adipose tissue appearance and distribution in the human fetus. Early Human Development 10, 1-11.

Postle AD, Al MDM, Burdge GC \& Hornstra G (1995) The composition of individual molecular species of plasma phosphatidylcholine in human pregnancy. Early Human Development 43, 47-58.

Poulos A, Darin-Bennett A \& White IG (1973) The phospholipidbound fatty acids and aldehydes of mammalian spermatozoa. Comparative Biochemistry and Physiology 46B, 541-549.

Rallidis LS, Paschos G, Liakos GK, Velissaridou AH, Anastasiadis G \& Zampelas A (2003) Dietary alpha-linolenic acid decreases C-reactive protein, serum amyloid A and interleukin-6 in dyslipidaemic patients. Atherosclerosis 167, 237-242.

Rallidis LS, Paschos G, Papaioannou ML, Liakos GK, Panagiotakos DB, Anastasiadis G \& Zampelas A (2004) The effect of diet enriched with alpha-linolenic acid on soluble cellular adhesion molecules in dyslipidaemic patients. Atherosclerosis 174, 127-132.

Roche HM \& Gibney MJ (1999) Long-chain n-3 polyunsaturated fatty acids and triacylglycerol metabolism in the postprandial state. Lipids 34, Suppl., S259-S265.

Salem N, Powlosky R, Wegher B \& Hibbeln J (1999) In vivo conversion of linoleic acid to arachidonic acid in human adults. Prostaglandins, Leukotrienes and Essential Fatty Acids 60, 407-410.

Salem N, Wegher B, Mena P \& Uauy R (1996) Arachidonic and docosahexaenoic acids are biosynthesized from their 18-carbon precursors in human infants. Proceedings of the National Academy of Science USA 93, 49-54.

Salonen JT, Salonen R, Ihanainen M, Parviainen M, Seppanen R, Kantola M, Seppanen K \& Rauramaa R (1988) Blood pressure, dietary fats, and antioxidants. American Journal of Clinical Nutrition 48, 1226-1232.

Sanders TA \& Roshanai F (1983) The influence of different types of omega 3 polyunsaturated fatty acids on blood lipids and platelet function in healthy volunteers. Clinical Science (London) 64, 91-99.

Sanders TA, Vickers M \& Haines AP (1981) Effect on blood lipids and haemostasis of a supplement of cod-liver oil, rich in eicosapentaenoic and docosahexaenoic acids, in healthy young men. Clinical Science (London) 61, 317-324.

Sanders TA \& Younger KM (1981) The effect of dietary supplements of omega 3 polyunsaturated fatty acids on the fatty acid composition of platelets and plasma choline phosphoglycerides. British Journal of Nutrition 45, 613-616.

Sauerwald TU, Hachey DL, Jensen CL, Chen H, Anderson RE \& Heird WC (1997) Intermediates in endogenous synthesis of
C22:6 63 and $\mathrm{C} 20: 4 \omega 6$ by term and preterm infants. Pediatric Research 141, 183-187.

Saunders DR \& Sillery JK (1988) Absorption of triglyceride by human small intestine: dose-response relationships. American Journal of Clinical Nutrition 48, 988-991.

Schrepf R, Limmert T, Claus Weber P, Theisen K \& Sellmayer A (2004) Immediate effects of $n-3$ fatty acid infusion on the induction of sustained ventricular tachycardia. Lancet 363, $1441-1442$

Sheaff-Greiner RC, Zhang Q, Goodman KJ, Giussani DA, Nathanielsz PW \& Brenna JT (1996) Linoleate, $\alpha$-linolenate, and docosahexaenoate recycling into saturated and monounsaturated fatty acids is a major pathway in pregnant or lactating adults and fetal or infant rhesus monkeys. Journal of Lipid Research 37, 2675-2686.

Shoda R, Matsueda K, Yamato S \& Umeda N (1996) Epidemiologic analysis of Crohn disease in Japan: increased dietary intake of n-6 polyunsaturated fatty acids and animal protein relates to the increased incidence of Crohn disease in Japan. American Journal of Clinical Nutrition 63, 741-745.

Simon JA, Fong J, Bernert JT \& Browner WS (1995) Serum fatty acids and the risk of stroke. Stroke 26, 778-782.

Simopoulos AP (2001) $n$-3 Fatty acids and human health: defining strategies for public policy. Lipids 36, S83-S89.

Sinclair AJ, Attar-Bashi NM \& Li D (2000) What is the role of $\alpha$ linolenic acid for mammals? Lipids 37, 1113-1123.

Singer P, Berger I, Wirth M, Godicke W, Jaeger W \& Voigt S (1986) Slow desaturation and elongation of linoleic and $\alpha$ linolenic acids as rationale of eicosapentaenoic acid-rich diet to lower blood pressure and serum lipids in normal, hypertensive and hyperlipidemic subjects. Prostaglandins Leukotrienes and Medicine 24, 173-193.

Sodergren E, Gustafsson IB, Basu S, Nourooz-Zadeh J, Nalsen C, Turpeinen A, Berglund L \& Vessby B (2001) A diet containing rapeseed oil-based fats does not increase lipid peroxidation in humans when compared to a diet rich in saturated fatty acids. European Journal of Clinical Nutrition 55, 922-931.

Sorensen NS, Marckmann P, Hoy CE, van Duyvenvoorde W \& Princen HM (1998) Effect of fish-oil-enriched margarine on plasma lipids, low-density-lipoprotein particle composition, size, and susceptibility to oxidation. American Journal of Clinical Nutrition 68, 235-241.

Sprecher H (2002) The roles of anabolic and catabolic reactions in the synthesis and recycling of polyunsaturated fatty acids. Prostaglandins, Leukotrienes and Essential Fatty Acids 67, 79-83.

Suzukawa M, Abbey M, Howe PR \& Nestel PJ (1995) Effects of fish oil fatty acids on low density lipoprotein size, oxidizability, and uptake by macrophages. Journal of Lipid Research 36, 473-484.

Tagawa H, Shimokawa H, Tagawa T, Kuroiwa-Matsumoto M, Hirooka Y \& Takeshita A (1999) Long-term treatment with eicosapentaenoic acid augments both nitric oxide-mediated and non-nitric oxide-mediated endothelium-dependent forearm vasodilatation in patients with coronary artery disease. Journal of Cardiovascular Pharmacology 33, 633-640.

Tang AB, Nishimura KY \& Phinney SD (1993) Preferential reduction in adipose tissue alpha-linolenic acid (18:3 omega 3 ) during very low calorie dieting despite supplementation with 18:3 omega 3. Lipids 28, 987-993.

Tang C, Cho HP, Nakamura MT \& Clarke SD (2003) Regulation of human $(\Delta-6$ desaturase gene transcription: identification of a functional direct repeat-1 element. Journal of Lipid Research 44, 686-695.

Thies F, Miles EA, Nebe-von-Caron G, Powell JR, Hurst TL, Newsholme EA \& Calder PC (2001a) Influence of dietary supplementation with long chain $\mathrm{n}-3$ or $\mathrm{n}-6$ polyunsaturated 
fatty acids on blood inflammatory cell populations and functions and on plasma soluble adhesion molecules in healthy adults. Lipids 36, 1183-1193.

Thies F, Nebe-von-Caron G, Powell JR, Yaqoob P, Newsholme EA \& Calder PC (2001b) Dietary supplementation with eicosapentaenoic acid, but not with other long chain n-3 or n-6 polyunsaturated fatty acids, decreases natural killer cell activity in healthy subjects aged $>55$ years. American Journal of Clinical Nutrition 73, 539-548.

Thies F, Nebe-von-Caron G, Powell JR, Yaqoob P, Newsholme EA $\&$ Calder PC (2001c) Dietary supplementation with $\gamma$-linolenic acid or fish oil decreases $\mathrm{T}$ lymphocyte proliferation in healthy older humans. Journal of Nutrition 131, 1918-1927.

Tilley SL, Coffman TM \& Koller BH (2001) Mixed messages: modulation of inflammation and immune responses by prostaglandins and thromboxanes. Journal of Clinical Investigation 108, 15-23.

Vermunt SHF, Mensink RP, Simonis AMG \& Hornstra G (2000) Effects of dietary $\alpha$-linolenic acid on the conversion and oxidation of $\left[{ }^{13} \mathrm{C}\right]-\alpha$-linolenic acid. Lipids 35, 137-142.

Vinton NE, Heckenlively JR, Laidlaw SA, Martin DA, Foxman SR, Ament ME \& Kopple JD (1990) Visual function in patients undergoing parenteral nutrition. American Journal of Clinical Nutrition 52, 895-902.

von Schacky C, Fischer S \& Weber PC (1985) Long-term effects of dietary marine omega-3 fatty acids upon plasma and cellular lipids, platelet function, and eicosanoid formation in humans. Journal of Clinical Investigation 76, 1626-1631.

Wallace FA, Miles EA \& Calder PC (2003) Comparison of the effects of linseed oil and different doses of fish oil on mononuclear cell function in healthy human subjects. British Journal of Nutrition 89, 679-689.

Weaver BJ, Corner EJ, Bruce VM, McDonald BE \& Holub BJ (1990) Dietary canola oil: effect on the accumulation of eicosapentaenoic acid in the alkenylacyl fraction of human platelet ethanolamine phosphoglyceride. American Journal of Clinical Nutrition 51, 594-598.

Wensing AG, Mensink RP \& Hornstra G (1999) Effects of dietary n-3 polyunsaturated fatty acids from plant and marine origin on platelet aggregation in healthy elderly subjects. British Journal of Nutrition 82, 183-191.

Wiegand RD, Koutz CA, Stinson AM \& Anderson RE (1991) Conservation of docosahexaenoic acid in rod outer segments of rat retina during n-3 and n-6 fatty acid deficiency. Journal of Neurochemistry 57, 1690-1699.

Williams CM (1997) Postprandial lipid metabolism: effects of dietary fatty acids. Proceedings of the Nutrition Society 56, 679-692.

Zhao G, Etherton TD, Martin KR, West SG, Gillies PJ \& Kris-Etherton PM (2004) Dietary alpha-linolenic acid reduces inflammatory and lipid cardiovascular risk factors in hypercholesterolemic men and women. Journal of Nutrition 134, 2991-2997. 